Laser-induced copper deposition from aqueous and aqueous-organic solutions: state of the art and prospects of research

This content has been downloaded from IOPscience. Please scroll down to see the full text. 2015 Russ. Chem. Rev. 841059

(http://iopscience.iop.org/0036-021X/84/10/1059)

View the table of contents for this issue, or go to the journal homepage for more

Download details:

IP Address: 195.19.236.218

This content was downloaded on 08/04/2016 at 09:59

Please note that terms and conditions apply. 


\title{
Laser-induced copper deposition from aqueous and aqueous - organic solutions: state of the art and prospects of research
}

\author{
V A Kochemirovsky, M Yu Skripkin, Yu S Tveryanovich, A S Mereshchenko, A O Gorbunov, \\ M S Panov, I I Tumkin, S V Safonov
}

Saint Petersburg State University

Universitetskaya nab. 7-9, 199034 Saint Petersburg, Russian Federation

\begin{abstract}
Information about the factors influencing laser-induced deposition of metals, primarily copper, from aqueous and aqueous-organic solutions are generalized and described systematically. Laser-induced deposition techniques and mechanisms of chemical and laser-induced deposition of local copper and other metal structures onto the dielectric surface are considered. The effects of the solution composition, the nature of the reducing agent and the properties of the dielectric surface on the deposition process are discussed. Possible photochemical reactions induced by laser radiation and the role of these reactions in the photoreduction of metals are considered. The key trends and prospects in the development of laserinduced chemical liquid phase deposition are mentioned.

The bibliography includes 132 references.
\end{abstract}

\section{Contents}

I. Introduction

1059

II. Chemical factors influencing chemical liquid phase deposition of copper

1060

III. Effect of dielectric surface properties

IV. Prospects and key trends of development of laser-induced liquid phase deposition technique

\section{Introduction}

Laser metal deposition is one of promising methods of metallization of dielectric surfaces. The state of the art of research in this field can be characterized as primary accumulation of basic knowledge. An advantage of laser deposition is that even the surface of wide band-gap $(>3 \mathrm{eV})$ dielectric materials can be metallized without any pretreatment, which is difficult to achieve by other methods.
One of the laser deposition techniques is laser-induced chemical liquid-phase deposition (LCLD). It is based on localized deposition of metal from a solution via chemical reduction of the metal or decomposition of its salt (complex) induced by laser radiation. Laser metal deposition from electrolyte solutions can be used to fabricate microand nanosized metal structures on the surface of dielectrics and semiconductors of different types. ${ }^{1}$
V A Kochemirovsky Candidate of Chemical Sciences, Associate Professor of the Chair of Laser Chemistry and Laser Material Science at the SPbSU. Telephone: +7(812)327-1504, e-mail: v.kochemirovsky@spbu.ru Current research interests: inorganic chemistry, laser chemistry, materials science.

M Yu Skripkin Candidate of Chemical Sciences, Associate Professor of the Chair of General and Inorganic Chemistry at the SPbSU.

Telephone: +7(812)428-4069, e-mail: m.skripkin@spbu.ru Current research interests: inorganic chemistry, solution chemistry. Yu S Tveryanovich Doctor of Chemical Sciences, Professor, Head of the Chair of Laser Chemistry and Laser Material Science at the SPbSU. Telephone: +7(812)428-7479, e-mail: yu.tveryanovich@spbu.ru Current research interests: laser chemistry, nanodispersed materials, thin films.

A S Mereshchenko Candidate of Chemical Sciences, Associate Professor of the SPbSU.

Telephone: +7(812)428-7479, e-mail: a.mereshchenko@spbu.ru Current research interests: photochemistry, laser chemistry, inorganic chemistry.
A O Gorbunov Post-graduate Student of the Chair of General and Inorganic Chemistry at the SPbSU.

Telephone: + 7(812)428-4069, e-mail: a.o.gorbunov@spbu.ru Current research interests: inorganic chemistry, solution chemistry. M S Panov Candidate of Chemical Sciences, Postdoc of the Chair of Laser Chemistry and Laser Material Science at the SPbSU.

Telephone: +7(812)428-7479, e-mail: m.s.panov@spbu.ru Current research interests: photochemistry, laser chemistry.

I I Tumkin Research Engineer of the same Chair.

Telephone: +7(812)428-7479, e-mail: i.i.tumkin@spbu.ru

Current research interests: laser chemistry, inorganic chemistry, materials science.

S V Safonov Candidate of Chemical Sciences, Assistant Professor of the same Chair.

Telephone: +7(812)428-7479, e-mail: s.safonov@chem.spbu.ru

Current research interests: laser chemistry, inorganic chemistry, materials science.

Received 11 November 2014

Uspekhi Khimii 84 (10) 1059 - 1075 (2015); translated by T N Safonova 
At first glance, laser chemical vapour deposition (LCVD), ${ }^{2}$ pulsed laser deposition (PLD), ${ }^{3}$ laser-induced film transfer technique (LIFT) ${ }^{4}$ and laser pyrolytic destruction of solids (LPDS) ${ }^{5}$ are alternatives to LCLD. Nevertheless, the LCLD technique has obvious advantages over the above-listed methods, such as

- it is cost-effective because expensive equipment is not required;

- small amounts of toxic wastes are produced;

- LCLD provides higher deposition rates compared with LCVD and LIFT.

Besides, LCLD can be accomplished in one step, if the surface to be metallized has a composite (two- or multiphase) structure or includes areas of substantially different compositions, ${ }^{6}$ or in two steps, if the surface preactivation is required. A considerable advantage compared to other methods using laser radiation is that it can be used to fabricate highly conducting metal structures. ${ }^{7,8}$

The LCLD technique can be employed to deposit the following metals onto the surface of various dielectrics: copper, silver, ${ }^{9}$ palladium, ${ }^{10}$ platinum, ${ }^{11}$ nickel, ${ }^{12}$ gold, ${ }^{13}$ chromium and tungsten. ${ }^{14}$ The copper deposition is of most practical interest because copper is widely used as a conducting material in microelectronics, as well as due to the catalytic activity of copper-based nanoparticles. ${ }^{15,16}$

In some cases, the specificity of laser-induced deposition provides new pathways of chemical reactions. ${ }^{17,18}$ Due to such features of laser-induced copper deposition as a high energy density and a considerable temperature gradient around the laser beam focus, side reactions and the decomposition of organic components of the solution can occur. ${ }^{13}, 18$ This is why the results of laser-induced deposition from most of known solutions, in which autocatalytic reactions take place, substantially differ from the results of standard chemical copper plating. The causes and mechanisms of these differences have been little studied. It is generally assumed that the mechanism of the laser-induced reaction is analogous to the autocatalytic mechanism. ${ }^{19}$ In some investigations, the influence of the components of the solution was not considered at all. In these works, the authors examined only the effects of the laser power and wavelength, ${ }^{20}$ the rate of laser beam scanning of the dielectric surface and the number of scans of the same area of the dielectric surface ${ }^{21}$ and obtained quite predictable results, such as an increase or decrease in the geometric sizes of deposited copper structures.

The methods of laser-induced chemical liquid-phase deposition can be arbitrarily divided into three groups.

1. One-step processes. The metal deposition is performed in one step. The metal is deposited directly from a solution onto the substrate using a thermally or photoinduced redox reaction in solution at the interface with a dielectric.

2. Two-step processes involving the laser-induced predeposition of a precious metal. In the first step, the laserinduced deposition of a precious metal (silver ${ }^{22}$ or palladium ${ }^{23}$ ) template is performed followed by chemical deposition of copper. The precious metal acts as a catalyst for the redox reaction between copper(II) and a reducing agent in solution. In this case, copper is deposited only onto the surface of the template thus forming a current-carrying strip.

3. Two-step processes involving the laser treatment of the material in air. Initially, the surface of the material subjected to metallization is treated by laser radiation in air. Then the material is placed in a hot copper- or nickelplating solution. Due to changes in the surface properties of the laser-irradiated areas, the metal is deposited only onto these areas. ${ }^{11}$

The laser-induced deposition of copper has been studied most extensively because this metal is of most interest to researchers as the cheapest highly conducting material for microelectronics, which, in addition, has catalytic properties and can be reduced from the ion in solution through thermochemical and photochemical routes. Almost all studies on the one-step laser-induced deposition of metal were performed with copper.

An analysis of the state of the art of investigations in the field of laser-induced deposition of metals shows that the following three groups of factors have an effect on the results of this process: ${ }^{1}$

- physical factors (laser power and wavelength, scan rate, temperature of the environment and solution);

- chemical factors (the composition of the solution, concentrations of the components, $\mathrm{pH}$, chemical reactions in solution, photochemical processes in solution, the characteristic features of complexation in aqueous-organic systems);

- surface properties of the dielectric substrate (structure, the presence of activated and catalytic centres, defect structure, phase composition, chemical properties of the components of the dielectric material).

Depending on the type of the dominant reaction mechanism, laser-induced deposition techniques are divided into photoinduced (photodecomposition of metal salts or complexes in solution is a dominant reaction) and thermally induced (photoprocesses play a minor role, and the metallization results from the high-temperature initiation of redox reactions involving a metal ion).

The above-listed factors and their influence on the copper plating process are briefly considered in the following sections.

\section{Chemical factors influencing chemical liquid phase deposition of copper}

II.1. Composition of the solution and reaction mechanisms

For a long time, the following reaction was the only one that was used for the laser-induced reduction of copper

$$
\begin{aligned}
& \mathrm{CuL}^{(n-2)-}+2 \mathrm{HCHO}+4 \mathrm{HO}^{-} \longrightarrow \\
& \longrightarrow \mathrm{Cu}^{0}+\mathrm{L}^{n-}+\mathrm{H}_{2}+2 \mathrm{HCOO}^{-}+2 \mathrm{H}_{2} \mathrm{O}
\end{aligned}
$$

where $\mathrm{L}$ is an organic ligand [usually the tartrate or ethylenediaminetetraacetate anion (EDTA)]; HCHO (formaldehyde) was added as the reducing agent in a 6-7.5-fold excess. ${ }^{18}$ Sulfate or chloride were most often employed as copper salts.

Reaction (1) was used long enough for chemical copper plating of pre-activated surfaces and is known as the 'copper mirror chemical reaction'. ${ }^{24}$ As applied to the laser-induced reduction of copper, this process was not efficient in preparing highly conducting finely dispersed copper structures with stable properties. The reaction with formaldehyde gave a deposit as a layer of copper cubic crystals fused via vertices and edges (Fig. 1), i.e., the deposit had a porous structure and low conductivity. ${ }^{18}$ 


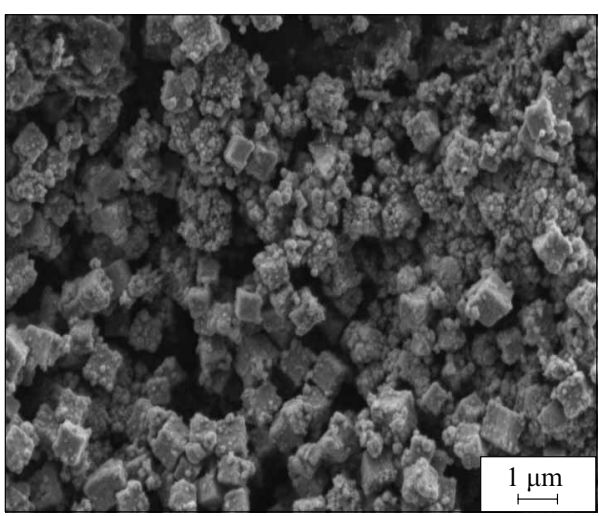

Figure 1. Deposit produced by laser-induced deposition of copper from the solution $0.01 \mathrm{M} \mathrm{CuCl}_{2}+0.011 \mathrm{M} \mathrm{KNaC} \mathrm{KH}_{4} \mathrm{O}_{6} \cdot 4 \mathrm{H}_{2} \mathrm{O}+$ $0.05 \mathrm{M} \mathrm{NaOH}+0.075 \mathrm{M} \mathrm{HCHO} .{ }^{18}$

Later on, it was found that much better performance can be achieved with polyols as reducing agents, the lower the reducing ability of polyol, i.e., the higher its reduction potential, the more monolithic and dispersed the copper deposits, and the electrical conductivity of the deposited copper (very stable on the time scale) is close to that of pure copper (Fig. 2). ${ }^{7,8,25}$

Similar results can be obtained by the addition of some types of hydrophilic nonionogenic surfactants, ${ }^{26,27}$ which have a hydrophilic-lipophilic balance (HLB) characterized by Griffin's HLB values of $11-12 .{ }^{28}$ Any types of ionogenic surfactants interfere with the deposition. ${ }^{29}$

It should be noted that the general approach to the determination of the composition of solutions was the same as that used for traditional formaldehyde solutions. It was believed that the solution for laser-induced deposition of copper should contain, in addition to a copper salt, components acting as a ligand, a reducing agent and a $\mathrm{pH}$ regulator. The functions of these components in metallization solutions are considered below.

Numerous compositions of nickel-plating solutions were proposed..$^{30}$ The deposition of nickel employing traditional solutions also involves a number of problems. The use of sodium hypophosphite as the reducing agent results in the co-deposition of a mixture of nickel and phosphorus, as well

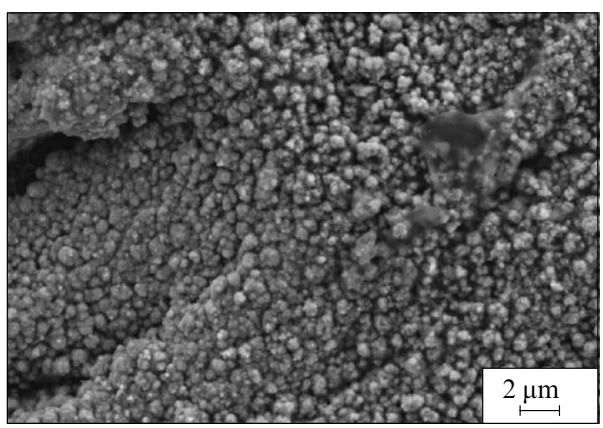

Figure 2. Deposit produced by laser-induced deposition of copper from the solution $0.01 \mathrm{M} \mathrm{CuCl}_{2}+0.05 \mathrm{M} \mathrm{NaOH}+$ $0.03 \mathrm{M} \mathrm{KNaC}_{4} \mathrm{H}_{4} \mathrm{O}_{6} \cdot 4 \mathrm{H}_{2} \mathrm{O}+0.075 \mathrm{M}$ xylitol (reducing agent). ${ }^{7,8,25}$ as, probably, phosphides; the use of boron-containing reducing agents leads to the co-deposition of boron.

\section{II.2. Metal salts}

In the conventional copper plating technique for the fabrication of printed circuit boards, $\mathrm{CuSO}_{4}$ is used to build-up a copper layer. ${ }^{31}$ The empirical dependence of the deposition rate $(r)$ of metallic copper (measured in micrometres of the film thickness per hour) on the copper ion concentration in solution for the chemical metallization ${ }^{32}$ takes the form

$$
r \sim[\mathrm{Cu}]^{0.4}
$$

where $[\mathrm{Cu}]$ is the concentration of the divalent copper complex with EDTA in solution.

However, an increase in the copper salt concentration in solution during the laser deposition not necessarily leads to an increase in the amount of deposited metal. As a rule, at high concentrations $(0.1 \mathrm{M}$ and higher) the topology of the deposited structures is deteriorated and the amount of deposited copper decreases with a further increase in the copper concentration. ${ }^{33}$

The investigation of the influence of the anionic composition of solutions on the results of laser deposition ${ }^{34}$ demonstrated that the anion has some effect on this process, in particular, when using solutions containing an alkali, a copper salt, a ligand (tartrate) and a reducing agent (formaldehyde). A comparison of the results of the liquid phase deposition of $\mathrm{CuSO}_{4}$ and $\mathrm{CuCl}_{2}$ showed that the electrical resistance of the deposits obtained from a $\mathrm{CuCl}_{2}$ solution is 3-4 times lower compared with the deposits produced from a $\mathrm{CuSO}_{4}$ solution in the power range of $250-350 \mathrm{~mW}$. This may be due to the two-electron character of the reduction of copper(II) to copper(0), which apparently proceeds through the formation of $\mathrm{Cu}(\mathrm{I})$ in solution $\left(\mathrm{Cu}_{\mathrm{aq}}^{+}\right)$. It is known that copper(I) in aqua complexes is unstable, but it is substantially stabilized upon complexation. The $\mathrm{Cu}_{\mathrm{aq}}^{+}$ion immediately disproportionates to $\mathrm{Cu}^{0}$ and $\mathrm{Cu}^{2+}$ (Ref. 35). In a $\mathrm{CuSO}_{4}$ solution, a colloidal metal solution is formed followed by the deposition of the metal onto the surface, the deposit being inhomogeneous. In a $\mathrm{CuCl}_{2}$ solution, the reduction of $\mathrm{CuCl}_{2}^{-}$anionic complexes will apparently give rise to polynuclear heterovalent intermediates $\mathrm{Cu}^{+1 / 0}-\mathrm{Cu}^{-}-\mathrm{Cu}^{+1 / 0}$, which will be adsorbed on the surface, thus improving the topology of the deposited copper structure.

The effect of the temperature on the deposition process was noted. ${ }^{34}$ Thus, an increase in the temperature of the solution in a cell from 25 to $45{ }^{\circ} \mathrm{C}$ led to an increase in the amount of deposited metal. This is indirect evidence of the occurrence of thermochemical processes in solution.

\section{II.3. Reducing agent}

The proposed mechanisms of metal reduction based on the results of investigations of chemical and electrochemical metallization are described in detail in the literature (see, for example, Refs 24, 25, 31 and 36).

An electrochemical theory was proposed ${ }^{37}$ to explain the catalytic effect of the metal surface on the chemical metallization process. According to this theory, the cathodic reduction of metal and the anodic oxidation of the reducing agent take place in certain areas of the catalyst surface. The catalyst promotes the electron transfer from 


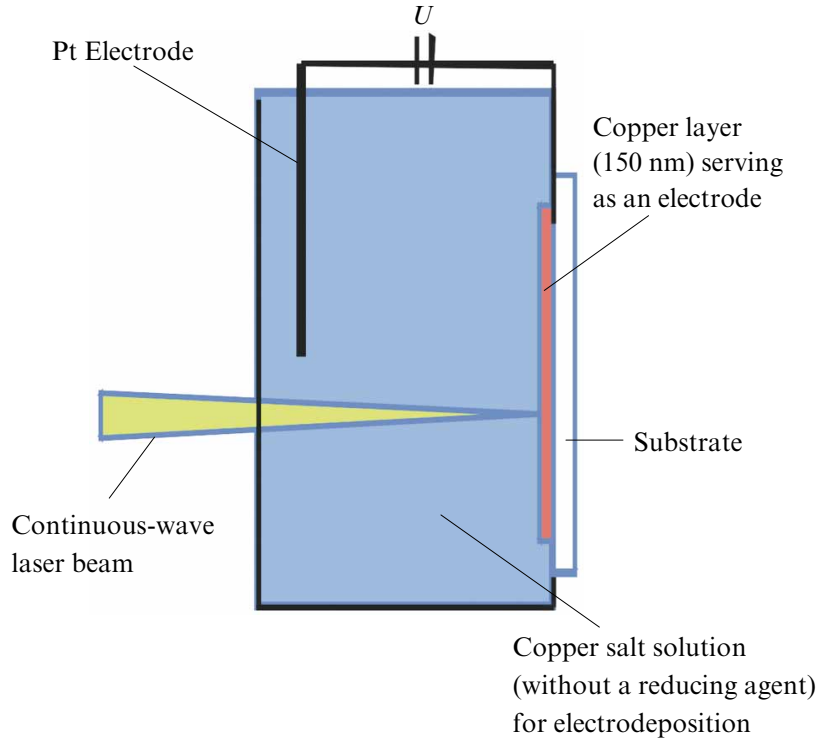

Figure 3. Chart of von Gutfeld's experiment on laser-induced electrochemical deposition of copper..$^{38-40}$

the reducing agent directly to the metal ion, which otherwise proceeds with difficulty.

In the chemical copper plating, hypophosphite, hyposulfite and hydrazine can be used, along with formaldehyde, to reduce copper (as well as nickel and some other metals). ${ }^{30}$ However, these compounds exhibit reducing properties only at elevated temperature. Besides, these reducing agents are usually not involved in autocatalytic processes, which could lead to the uncontrolled deposition of metal in the bulk of the solution as soon as the required temperature is reached. Hypophosphite and hydrosulfite exhibit reducing properties in an acidic medium; formaldehyde and hydrazine, in an alkaline medium.

The reduction of copper using formaldehyde as the reducing agent occurs mainly on grains and surfaces of the already deposited copper, rather than throughout the bulk of the solution (autocatalytic reaction). However, the requirement of autocatalysis is not universal. It might be supposed that the number of reducing agents that can be involved in the metallization is much larger than those used in conventional chemical and electrochemical reactions. This is associated with the influence of laser radiation on the potentials of redox reactions in solution.

In experiments performed by von Gutfeld and co-workers, ${ }^{38-40}$ the laser beam was focused onto the copper electrode/copper sulfate solution interface (Fig. 3). The second electrode was placed in a solution. An external voltage $(U)$ was applied to a closed circuit. At an insignificant external voltage, laser irradiation can induce a potential jump (E) of about $0.4 \mathrm{~V}$ at the copper/electrolyte solution interface and the rate of copper deposition in the irradiated area increases by a factor of 1000 . The authors attributed this effect to the thermal factor (kinetics of deposition) and to the stirring of the solution. However, the simplest calculations by the Nernst equation showed that the potential change in the solution due to its heating can reach only $0.1-0.15 \mathrm{~V}$. Besides, a high thermal conductivity of copper should facilitate the deposition of wide copper structures, which is inconsistent with the experimental data on the localized laser-induced electrodeposition.

The kinetics of the photochemical component of the process is weakly related to the temperature factor and depends to a greater extent on the parameters of laser radiation (power and wavelength). ${ }^{41}$

The improvement of the topology of copper structures at lower reduction potentials of the polyol used was explained ${ }^{25}$ based on the calculated potential shift of the electrical circuit and the fact that the calculated value is consistent with the experimental data obtained by von Gutfeld and co-workers ${ }^{38-40}$ in the study of electrodeposition. The redox reactions with the participation of reducing agents with rather low standard reduction potentials (formaldehyde, ethanol and so on; Table 1) can already occur in solution, and the treatment of this solution by laser radiation can give rise to non-localized deposition of copper.

In the reactions using reducing agents with a low reduction potential (xylitol, sorbitol), the potential difference sufficient for the redox reaction between copper and an organic reducing agent to proceed can be achieved only on the metallized dielectric surface, resulting in the localized deposition of copper (Fig. 4). The formation of copper nuclei will be determined by the defect formation in dielectrics under laser irradiation by the mechanism which has been described in detail by Shafeev and co-workers. ${ }^{42,43}$ This provides additional support to the hypothesis that von Gutfeld's potential shift is attributed not only to the thermal effect of laser radiation but also to the contribution of electron photoemission from the deposited metal surface induced by laser radiation. ${ }^{44}$

This interpretation can be extended to the influence of the stability of a copper complex in solution and the copper concentration on the laser deposition process, ${ }^{45}$ the more so since polyols can also be coordinated to copper ions in solution like classical ligands.

Table 1. Standard reduction potentials of reducing agents used for $\operatorname{LCLD}\left(E_{0}\right)$ and the reduction potential difference between the $\mathrm{Cu}^{2+} / \mathrm{Cu}^{\circ} \mathrm{couple}$ and the reducing agent in solution under standard conditions $\left(\Delta E_{0}\right)$ and at $80{ }^{\circ} \mathrm{C}(\Delta E)$, as well as at the metal/solution interface..$^{1,25}$

\begin{tabular}{|c|c|c|c|c|}
\hline Reducing agent & $-E_{0}^{\mathrm{RCH}_{2} \mathrm{OH} / \mathrm{RCOO}-} / \mathrm{V}$ & $\Delta E_{0} / \mathrm{V}$ & $\begin{array}{l}\Delta E \text { (calculated in solution) } \\
/ \mathrm{V}(+0.1 \mathrm{~V})\end{array}$ & $\begin{array}{l}\Delta E \text { (calculated according } \\
\text { to von Gutfeld at the copper/ } \\
\text { solution interface) } / \mathrm{V}(+0.4 \mathrm{~V})\end{array}$ \\
\hline Formaldehyde & 0.98 & 0.78 & 0.88 & 1.28 \\
\hline Ethanol & 0.56 & 0.36 & 0.46 & 0.86 \\
\hline Ethylene glycol & 0.54 & 0.34 & 0.44 & 0.84 \\
\hline Glycerol & 0.45 & 0.24 & 0.34 & 0.74 \\
\hline Xylitol & 0.10 & 0.10 & 0.20 & 0.60 \\
\hline Sorbitol & 0.10 & 0.10 & 0.20 & 0.60 \\
\hline
\end{tabular}




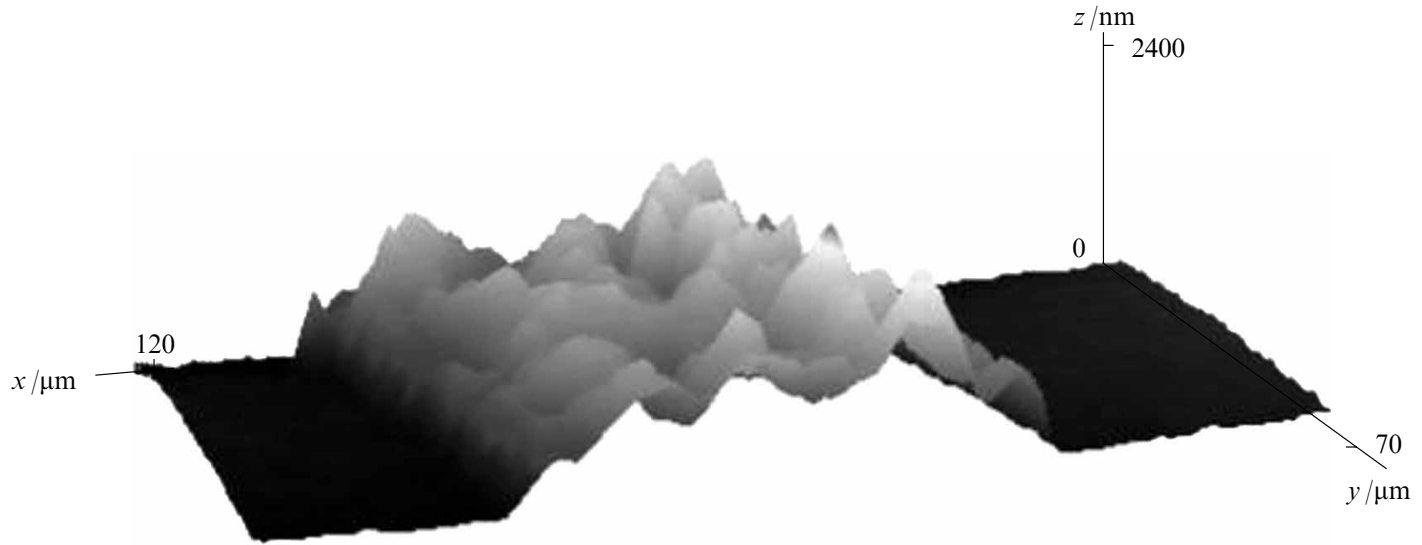

Figure 4. Cross-section profile of a copper strip produced by laser-induced deposition of copper from a $0.01 \mathrm{M} \mathrm{CuCl}_{2}+0.011 \mathrm{M}$ EDTA $+0.04 \mathrm{M} \mathrm{C}_{3} \mathrm{H}_{8} \mathrm{O}_{3}+0.5 \mathrm{M} \mathrm{NaOH}$ solution onto glass ceramics. ${ }^{7}$

The absorption of radiation by solution components and the rapid solution heating can give rise to side reactions, in particular, reactions accompanied by extensive gas formation. The presence of gases is a serious obstacle for laser deposition of metals because they lead to defocusing of the laser beam and interfere with the diffusion of reactants to the reaction zone. ${ }^{46}$

\section{II.4. Ligands}

The effect of the ligands on the laser-induced metal reduction is a big topic for research and experimental studies because the variation of the ligands is most suitable for controlling the process in order to localize it either in the bulk of the solution or on the dielectric surface, as well as with the aim of changing the balance between photo- and thermal components. Moreover, in the general case, the reducing agent is not a necessary component of the solution for a laser-induced process, and the ligand can act as the reducing agent and simultaneously participate in complexation and, vice versa, components with strong coordinating ability are the best reducing agents. ${ }^{47,48}$

The copper reduction in solutions which do not contain a component acting as a reducing agent was described by Ahrland and Tagesson. ${ }^{35}$ It should be noted that the application of alternative methods (chemical or electrochemical) for performing this reaction was not described in the literature. This fact was partially explained in the studies published earlier. ${ }^{38,49,50}$ The kinetics of thermochemical processes induced by laser heating of chemically reactive media is associated mainly with the following two factors: the occurrence of specific reactions and the mutual influence of the chemical state of the medium and the energy and mass transfer in the laser radiation field.

It was shown ${ }^{45}$ that the stability of the metal complex is of great importance for the localization of laser deposition at the laser focus. The ligands that form rather stable donor-acceptor bonds with metal ions perform two functions:

- prevent the deposition of metal hydroxide if the reduction occurs in an alkaline medium;

- decrease the standard reduction potential $\mathrm{M}^{n+} / \mathbf{M}^{0}$ to inhibit uncontrolled reduction throughout the bulk of the solution.
An alkaline medium is most often used to decrease the standard reduction potential of the reducing agent in solution. Therefore, an increase in the $\mathrm{pH}$ value results in that the potential difference between the oxidizing and reducing agents becomes positive and the reduction of metal is thermodynamically allowed. Since the functions of a $\mathrm{pH}$ regulator are very limited, its influence on the process has not been studied in detail. It was found ${ }^{36}$ that the chemical copper plating should be performed at $\mathrm{pH}$ $12.2-12.7$. These values were used in many experiments on laser deposition and were believed to be optimal.

In recent studies, yet another important function of the ligand was revealed. Thus, the ligand can control the localization of metal deposition. ${ }^{45}$ The narrowest copper conductors with sharp edges and high-quality topology can be produced by the addition of complexes with high stability constants to the solution.

The metal in a stable complex can be reduced only at high temperature or by decreasing the activation barrier by means of a catalyst. An oxalate ion, ammonia and glycerol can be used as ligands. ${ }^{37}$ However, salts of tartaric acid (potassium and sodium tartrates) or ethylenediaminetetraacetic acid are most commonly employed for this purpose..$^{51}$ After the addition of a ligand, metal is not always deposited from the solution in the bulk because of a small potential difference, but this difference may be increased in a local area by the thermal action of laser radiation. It was hypothesized that the electromotive force of a galvanic concentration cell also makes a considerable contribution to the change in the potential due to local changes in the activity of potential-forming ions in solution. ${ }^{38}$ The change in the activity, in turn, is associated with a change in the ion concentration in solution due to thermal diffusion induced by inhomogeneous laser heating. ${ }^{49}$ The sign of the thermal diffusion constant in solutions is such that positively charged metal ions usually migrate from less heated to more heated areas. ${ }^{50}$ According to experiments performed by von Gutfeld, ${ }^{38}$ the potential shift leads to a local change in the potential difference in the irradiated area and local deposition of metal.

In unstable metal complexes, the reduction is thermodynamically allowed without laser radiation. The heating of the solution will cause the reduction in the bulk of the 
solution, while the deposition of local structures on the surface will not take place.

\section{Effect of dielectric surface properties}

The LCLD process can be driven be a classical nucleation mechanism in the bulk of the solution or occur through the formation of atomic crystallization centres on either defects or activated fragments of the dielectric surface followed by the accretion (coalescence) through an autocatalytic mechanism.

The average distance between the nearest copper complexes was shown to be $\sim 3 \mathrm{~nm}$ even in a $0.01 \mathrm{M}$ solution of a copper complex. ${ }^{52}$ Evidently, under these conditions the nucleation process is statistically unlikely due to fluctuations in the bulk. Nevertheless, a significant contribution of the nucleation in the bulk is clearly seen in the case of deposition of metal from solutions containing formaldehyde as the reducing agent. This type of nucleation is observed in photolytic deposition processes. This fact was confirmed in the studies, ${ }^{53,54}$ in which the formation of a crystalline phase of the metal in an autocatalytic solution by a nucleation mechanism under non-localized UV radiation was confirmed by several independent methods, including powder X-ray diffraction.

In this case, it can be supposed that the problem of the local formation of a crystalline metal precipitate on the dielectric surface is in creating crystallization centres on the dielectric surface in such amount per unit surface area as to make the reduction through these centres thermodynamically favourable. Surface defects of the crystal after laser irradiation can serve as activation centres. Taking into account that, according to different estimates, this amount for semiconductors is usually in the range of $10^{11}-10^{15} \mathrm{~cm}^{-2}$ (see Refs 55 and 56), the laser action on the dielectric surface should lead to a considerable (by $1-3$ orders of magnitude) increase in the number of surface defects in order to form local deposited structures on the surface.

The microscopic mechanism of the formation of active centres may be of different nature depending on the surface activation strategy. The formation of an active centre is determined by the following two main factors.

1. Local changes in the energy spectrum of the electronic subsystem of the dielectric substrate surface. This mechanism is as follows: an external physical action gives rise to a non-equilibrium configuration of the electronic subsystem, which is accompanied by a change in the potential relief in a local area of the dielectric surface. This results in the formation of new higher-energy local nanostructures, which have rather labile electronic subsystems inducing the electron transfer from the reducing agent to the oxidizing one. ${ }^{52}$ Laser radiation is one of such actions. ${ }^{1,10,11}$ This type of activation is arbitrarily referred to as physical.

2. The insertion of an atom, a molecule or a group of atoms, which facilitates the charge transfer from the oxidizing agent to the reducing one, into the structure of the surface layer. The insertion can occur through the adsorption, chemosorption, a chemical reaction, by means of catalyst pre-deposition and so on. This activation mode can be arbitrarily considered as chemical. ${ }^{55,56}$ These methods are described in detail in numerous publications (see, for example, Refs 24, 31 and 36) and there is no need to go to the heart of the matter because the results of chemical activation are, for the most part, eliminated by laser radiation.

All known methods of activation of dielectric surfaces can be assigned to one of the above-mentioned types of interaction. Different surfaces can be activated to a different degree by both physical and chemical methods.

The laser activation of the dielectric surface can be performed in two ways, using a two- or one-step procedure. The two-step laser activation has long been employed by Shafeev. ${ }^{11,20}$ In recent years, the one-step approach was used in many works. ${ }^{7,8,17,18,34}$ The two-step method involves the laser pre-treatment of the dielectric surface in air followed by its immersion in a solution and the deposition of metal on the defects that formed. The one-step approach is based on the scanning of the dielectric surface by a focused laser beam directly in a solution containing a metal salt and a reducing agent.

The two-step method is a typical example of the physical activation of the dielectric surface, whereas the localized lasing mode implemented in the one-step approach makes it possible to combine the physical and chemical activation in one universal laser deposition technique.

The model of activation developed in accordance with Shafeev's concepts ${ }^{20}$ assumes that the ablation of dielectrics is accompanied by local changes in the electronic and chemical structure of such its areas that have been subjected to laser radiation. This is attributed to the following factors:

- the formation of oxygen vacancies in oxide materials. When treated with a laser, the oxide material loses some oxygen due to rapid heating. Since the time of laser irradiation is short, the rapid heating is followed by rapid cooling and the diffusion limitations, which hinder rapid recombination of metal atoms and atmospheric oxygen, give rise to metastable oxygen vacancies. Metal atoms in the oxide material serve as crystallization centres;

- bending of the energy bands of the dielectric under thermal and light irradiation treatment. The quenching of the material by laser radiation leads to the bending of the configuration of the valence band and the conduction band of the dielectric, resulting in its activation; ${ }^{20}$

- laser action by a one-step mechanism gives rise to activation centres as pre-deposited metal atoms or other groups ${ }^{6}$ with high electrical conductivity.

Strictly speaking, the latter phenomenon should be assigned to the mechanism of chemical activation. However, as mentioned above, the one-step laser activation process combines both processes and integrates the features of physical and chemical methods.

There are different types of surfaces. Some surfaces are naturally ready for laser metallization, i.e., initially contain a sufficient amount of active centres, whereas other surfaces should necessarily be pre-activated. The surfaces of dielectrics, which are always inert to metallization in the inactivated state, belong to the latter type.

A metal ion or a small metal cluster reduced on the dielectric surface can serve as the catalyst for the further reduction in solution in the absence of laser radiation. The character of the catalysis remains the same. Thus, the catalyst facilitates the charge transfer from the reducing to oxidizing agent but this process occurs through the predeposited metal rather than across the dielectric surface (Fig. 5). ${ }^{37}$ This process is usually referred to as the autocatalytic deposition. 


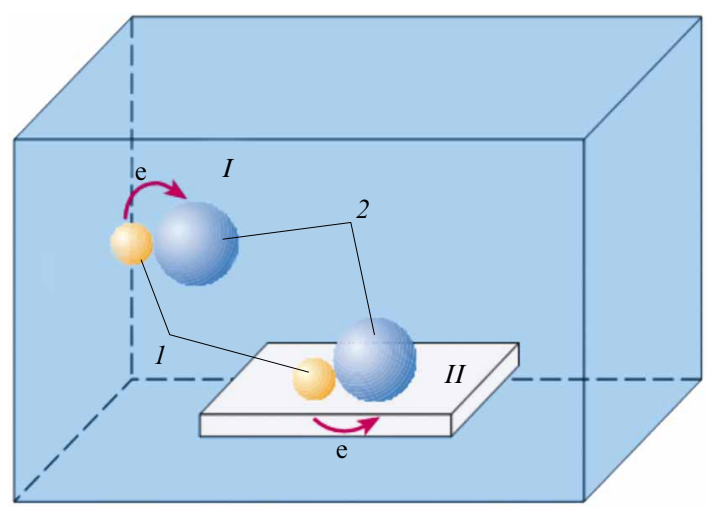

Figure 5. Electron transfer from the reducing agent to the oxidizing agent in the bulk of the solution $(I)$ and through the activated metallized surface $(I I) \cdot{ }^{37}$

(1) Reducing agent; (2) oxidizing agent.

The majority of the studies have focused on the effect of the surface properties on the two-step laser deposition. For instance, the laser-induced method was developed for the two-step nickel plating of dielectric and semiconductor surfaces. ${ }^{57}$ The surface area of diamond, which was activated by a copper vapour laser in air $(510 \mathrm{~nm})$ or by a $\mathrm{KrF}$ laser $(248 \mathrm{~nm})$, was then subjected to selective metallization by placing in a solution of nickel hypophosphite for the chemical reduction. The effect of the laser surface activation is stable over time and disappears only upon heating of the sample to $350-400{ }^{\circ} \mathrm{C}$ for $3 \mathrm{~h}$. It was also shown ${ }^{58}$ that the laser etching of the $\mathrm{SiC}$ surface both in air and when exposed to a liquid phase [dimethyl sulfoxide (DMSO), $\mathrm{H}_{2} \mathrm{O}, \mathrm{N}_{2} \mathrm{H}_{4}$ ] makes the surface catalytically active and facilitates the selective deposition of nickel and copper from the appropriate solutions. It was found that the irradiated area acquires a layered structure: the upper layer consists of $\mathrm{SiO}_{x}$, the intermediate layer is composed of $\mathrm{Si}$ clusters, and amorphous $\mathrm{SiC}$ constitutes the lower layer. It is the $\mathrm{Si}$ clusters that serve as catalytic centres initiating the deposition of metals. A similar two-step process can be applied to metallize $\mathrm{SiTiO}_{3}, \mathrm{PbTi}_{1-x} \mathrm{Zr}_{x} \mathrm{O}_{3}$, $\mathrm{Al}_{2} \mathrm{O}_{3}, \mathrm{ZrO}_{2}, \mathrm{AlN}$ and $\mathrm{LiNbO}_{3}$ surfaces. ${ }^{20}$

However, not all dielectric surfaces can be subjected to two-step activation. Thus, Shafeev ${ }^{20}$ noted that $\mathrm{SiO}_{2}$ and $\mathrm{MgO}$ cannot be activated in air followed by the immersion of the substrate in a metallization solution. Meanwhile, experiments on the laser metallization of oxide and quartz glasses demonstrated that the one-step copper plating and activation of glassy $\mathrm{SiO}_{2}$ can be performed. ${ }^{1,13,34}$

Apparently, it is the difference in the activation mechanisms in air and in solution ${ }^{51,59,60}$ that is responsible for the observed difference in the results of activation of silicon oxygen surfaces. The impossibility of activation of $\mathrm{MgO}$ is most likely attributed to chemical instability of $\mathrm{MgO}$ in an alkaline copper plating solution due to the formation of $\mathrm{Mg}(\mathrm{OH})_{2}$.

It should also be taken into account that Shafeev performed many studies using single-crystal materials, whereas polycrystalline, glassy and polymeric substrates were employed in other studies in the field of LCLD. Therefore, the results of activation of the substrate and the subsequent deposition onto the substrate cannot be pre- dicted in advance for the laser metallization of dielectrics, which have the same chemical composition and chemical properties, but differ in the crystal or phase structure.

It is important to mention features of laser activation common to all dielectrics. Once activated, the surface of the sample retains the ability to reduce metals from a solution for the chemical decomposition over a long period of time; at room temperature this ability is retained for several years. ${ }^{20,57,58}$ The catalytic activity of ablated areas disappears upon the annealing of the sample in air or under an oxygen atmosphere for several hours. The metal deposited onto the activated areas of the surface can be removed by chemical etching (for example, dissolved in $\mathrm{HCl}$ or $\mathrm{HNO}_{3}$ ) and then again deposited onto the same activated area of the surface. ${ }^{20,57,58}$

Activated metal atoms or clusters on the dielectric surface can appear not only as a result of the loss of oxygen atoms from oxides. This was observed, in particular, on AlN ceramics, which is decomposed under UV excimer laser radiation to form metallic aluminium even when a low energy flux of about several Joules per square centimetre is used. ${ }^{61,62}$

At an energy density of $2-4 \mathrm{~J} \mathrm{~cm}^{-2}$ ( $\mathrm{XeCl}, \mathrm{ArF}$ and $\mathrm{KrF}$ lasers), irradiated areas of the ceramics become able to reduce $\mathrm{Cu}$, Ni and other metals from the appropriate solutions for chemical metallization. The metal deposition starts in some areas of the ablated surface, whereas a continuous metallic film is formed through coalescence of individual metal islands during lateral growth. It was shown that the $\mathrm{XeCl}$-laser-induced ablation in air gives rise to metal islands on the $\mathrm{Al}_{2} \mathrm{O}_{3}$ surface, resulting in its activation. ${ }^{63}$

On the whole, the influence of the nature of the substrate on the results of laser-induced deposition has not been studied systematically as yet. Nevertheless, there is no doubt that the structure and the physical and chemical properties of the substrate are among the key factors responsible for the rate and outcome of the localized reduction of metal on the dielectric surface.

\section{Prospects and key trends of development of laser-induced liquid phase deposition technique}

The outcome of LCLD arises from to two groups of processes induced by laser radiation:

- processes in solutions, in which the redox reaction proceeds; such processes are determined by the ionic forms and superfast reactions involving metal ions;

- processes on the dielectric surface at temperatures much higher than the boiling points of aqueous and nonaqueous solutions. Presumably, these processes are responsible for the 'preparation' of the surface to deposition and the formation of activation and catalytic centres for the reduction of metal; such processes depend on the physical and chemical properties of the dielectrics.

\section{IV.1. Processes in solution}

Processes in solution take a much longer time than the residence time of a certain microvolume of the solution and the adjoining dielectric surface in the laser radiation field. A laser exerts mainly the initiating action on the deposition by forming surface or bulk catalytically active clusters. ${ }^{11}$ Only in this case, one can observe non-equilibrium processes that give results interesting from a scientific point of view. ${ }^{13,17,18}$ 
Once the microvolume comes out from the radiation field, the reaction develops in accordance with canonical thermodynamics of equilibrium processes. For this reason, the prospects of further investigations in the field of LCLD should primarily be based on these concepts. This is illustrated below in detail in relation to copper-containing solutions, but such considerations are true for any metal.

To optimize the laser-induced chemical liquid phase deposition of copper, it is necessary to understand the state in which the metal ions exist in solution depending on the composition of the solvent, the type of the counterion, the nature of the ligand and the presence of various modifying agents, which have an effect on the structure of the solution. Solutions of copper salts are widely studied in the solution chemistry and coordination chemistry. Let us refer to the classical work of Bjerrum, ${ }^{64}$ who developed an approach to the description of the stepwise complexation in solution in relation to amino complexes of copper. Later on, these objects have continued to attract great interest. Three main areas of fundamental research on copper salt solutions can be arbitrarily distinguished:

- structural studies (determination of the composition and structure of the solvation sphere);

- determination of the thermodynamic characteristics of solvation processes;

- studies of the complexation of copper ions with various ligands.

These three fields of research are briefly considered below. Taking into account the specificity of experiments on the laser-induced deposition, we confine ourselves mainly to the analysis of oxygen-donor solvents.

Numerous studies dealing with this issue hold to the idea that a decrease in the coordination number to 4 and the change to a square-planar configuration of the complexes facilitate the reduction of copper ions due to elimination of the endothermic contribution of desolvation of the $\mathrm{Cu}^{2+}$ ion, and as a result of lower steric hindrance to interaction of the reducing agent with the metal centre and the possibility of decreasing the potential barrier of the reaction. Therefore, the problem of the optimization of laser copper plating can be reduced to the search for ligands providing the above-mentioned steric parameters of the copper ion coordination.

Most of studies in this area were carried out in aqueous solutions. A high charge density on the doubly charged metal cation is responsible not only for the high energy of its hydration (the recommended value $\left.\Delta G_{\mathrm{hyd}}^{0}=-1020 \mathrm{~kJ} \mathrm{~mol}^{-1}\right)^{65}$ but also for a strong polarizing action, which results in a substantial polarization of coordinated water molecules and allows hydrolytic processes to occur. The following equilibria between aqua and hydroxo complexes of copper(II) are observed in solutions: ${ }^{32}$

$$
\begin{aligned}
& {\left[\mathrm{Cu}\left(\mathrm{H}_{2} \mathrm{O}\right)_{6}\right]_{\mathrm{aq}}^{2+} \rightleftharpoons\left[\mathrm{Cu}\left(\mathrm{H}_{2} \mathrm{O}\right)_{5} \mathrm{OH}\right]_{\mathrm{aq}}^{+}+\mathrm{H}_{\mathrm{aq}}^{+}} \\
& 2\left[\mathrm{Cu}\left(\mathrm{H}_{2} \mathrm{O}\right)_{6}\right]_{\mathrm{aq}}^{2+} \rightleftharpoons\left[\mathrm{Cu}_{2}\left(\mathrm{H}_{2} \mathrm{O}\right)_{8}(\mathrm{OH})_{2}\right]_{\mathrm{aq}}^{2+}+2 \mathrm{H}_{\mathrm{aq}}^{+}+2 \mathrm{H}_{2} \mathrm{O}
\end{aligned}
$$

the hydrolysis constant $\left(K_{\mathrm{h}}\right)$ is $3.2 \times 10^{-2}$

The formation of hydroxo complexes competes with other complexation processes in solution, including the formation of complexes with reducing agents. However, the small value of $K_{\mathrm{h}}$ indicates that hydrolysis processes in copper salt solutions are quite insignificant, and their contribution can easily be eliminated by a slight acidification of the solution. The deprotonation of deposits requires that the reduction be performed in an alkaline medium. This can be compensated using chelating ligands such as polyols, a tartrate ion, EDTA and so on. Meanwhile, an increase in the temperature leads to a substantial acceleration of the hydrolysis and hydrolytic polymerization of copper. These processes, along with thermal instability of hydroxo complexes, which finally leads to the deposition of copper oxide from the solution, can substantially interfere with the laserinduced deposition at high temperatures. ${ }^{36,66}$

Although the coordination number 6 is traditionally assigned to the $\mathrm{Cu}^{2+}$ ion in water and the elongated tetragonal bipyramid (coordination $4+2$ ) is assumed to be a characteristic shape of the coordination polyhedron, the coordination number 5 (square pyramidal configuration) was assigned to a copper ion in some recent studies. ${ }^{67}$ Persson et al. ${ }^{68}$ studied an aqueous solution of copper perchlorate acidified with perchloric acid and showed that the $(4+2)$ coordination of the copper ion is highly probable. They also determined the main structural parameters of the hydrated cation [the $\mathrm{Cu}-\mathrm{O}$ distances in the equatorial plane are 1.955(5) $\AA$; in the axial positions, 2.30(3) A]. The relationships between these parameters and the rate of metal reduction on clusters that are produced by the laser scanning of the dielectric surface are of great scientific interest.

In most cases, the laser-induced deposition is performed from aqueous solutions. However, Inada et al. ${ }^{69}$ showed that the use of such solvents as, for example, 1,3-dimethylpropyleneurea and 1,3-dimethyl-2-oxohexahydropyrimidine, induce strong steric hindrance to $(4+2)$ coordination, resulting in a decrease in the solvation number of the copper ion to 4 . Such steric hindrance is likely to facilitate the reduction of copper(II) to copper(I), which will lead to a decrease in the endothermic contribution of the desolvation of the cation. It cannot be ruled out that it is this reduction of copper that is the rate-limiting step of the overall reduction of copper both in the bulk of the solution and on the dielectric surface.

A change in the nature of the solvent leads to an insignificant change in the thermodynamics of the solvation of the doubly charged copper cation, whereas this effect is more pronounced for the singly charged copper cation. In terms of Pearson's hard and soft acid and base principle, the $\mathrm{Cu}^{+}$ion belongs to soft acids ${ }^{70}$ and, consequently, it will be better solvated by soft bases. A $\mathrm{X}=\mathrm{O}$ double bond ( $\mathrm{X}=\mathrm{C}$, $\mathrm{S})$ is responsible for the softness of such solvents as $N, N$ dimethylformamide (DMF), DMSO, dimethylacetamide (DMA) and acetone. The addition of these $\mathrm{Cu}^{+}$-stabilizing solvents to the solution should lead also to the deceleration of the disproportionation

$$
2 \mathrm{Cu}^{+} \rightleftharpoons \mathrm{Cu}^{2+}+\mathrm{Cu}^{0}
$$

and to a certain extent prevent the photo- or chemical reduction of $\mathrm{a} \mathrm{Cu}^{+}$ion to metal and, consequently, suppress the bulk crystallization of copper. Therefore, in the nearest future investigations of the LCLD reaction in nonaqueous solutions should attract much attention with the aim of changing the ratio of the bulk to surface components of the reaction towards the latter component.

The complexation of $\mathrm{Cu}^{2+}$ ions with various ligands, primarily in aqueous solutions, has been extensively inves- 
tigated. The most well-studied halide complexes of copper are characterized by low stability constants in aqueous solutions $(K)$, which, as mentioned above, can interfere with the deposition of local copper structures in laserinduced reduction processes. Based on the analysis of the published data, the values $K_{1}=4.37, \quad K_{2}=0.36$, $K_{3}=3.98 \times 10^{-2}$ and $K_{4}=3.98 \times 10^{-3}$ can be recommended for chloro complexes (due to low stability constants, these values differ by an order of magnitude even for the first complexation step); ${ }^{71}$ for bromo complexes in aqueous solutions, the stability is approximately an order of magnitude lower and, as a consequence, the variation in the values is much larger. This problem can be solved using organic or mixed aqueous organic solvents instead of water. For example, the stability constants of chloro complexes in DMF are 3-13 orders of magnitude larger compared with those in water. Besides, as can be seen in Table 2, the use of non-aqueous solvents results in a change from the octahedral $(4+2)$ coordination to the tetrahedral environment of the copper ion, which, as mentioned above, reduces endothermic effects associated with the desolvation and facilitates the reduction of the metal. $47,48,72,73$

The shape of the coordination polyhedron (the geometry of the environment) of the copper ion in halide complexes in water and in some non-aqueous solvents (see Table 2) was determined from the results of molecular absorption spectroscopy (electronic absorption spectroscopy). $23,25,29,31,33,74-84$

In some cases, there is no consensus on the shape of the coordination polyhedron of the copper ion in solution probably due to the difference in the experimental conditions used (different supporting ions, concentrations).

The introduction of halides of singly charged cations as additives into a solution has a considerable effect on the distribution of acido complexes and even on the shape of the coordination polyhedron of a copper ion. Ahrland and Tagesson ${ }^{35}$ studied the effect of the outer-sphere cation on the shape and composition of halide complexes of copper and demonstrated that the change in the structure-breaking effect of an alkali metal ion on water in the series

$$
\mathrm{Cs}^{+}>\mathrm{Rb}^{+}>\mathrm{K}^{+}>\mathrm{Na}^{+}>\mathrm{Li}^{+}
$$

is accompanied by an increase in the percentage of higher chloro complexes in solution, whereas the addition of caesium chloride causes the equilibrium between the octaand tetrahedral configurations observed for the tetrachlorocuprate anion to be almost completely shifted toward the latter one. ${ }^{35}$

A similar situation is observed for tetrabromo complexes. Thus, the square-planar configuration is typical of complexes containing lithium as the outer-sphere cation, whereas the tetrahedral configuration is observed for complexes with the bulkier tetra-n-butylammonium cation. ${ }^{85}$ It should be noted that an increase in the concentration stability constants for acido complexes, as well as a decrease in the coordination number to four, particularly in the case of the tetrahedral configuration of the coordination polyhedron, should promote the reduction of $\mathrm{Cu}^{2+}$ to $\mathrm{Cu}^{+}$ (halide complexes of singly charged copper are known to be highly stable, the tetrahedral configuration of the starting complexes makes the desolvation and structural rearrangement energetically more favourable), i.e., should have the same effect on the laser-induced reduction as non-aqueous solvents.

The study of saturated solutions of copper halide complexes by the extended X-ray absorption fine structure (EXAFS) techniques ${ }^{83}$ demonstrated that the outer-sphere cation can substantially influence also the distribution of halide ligands and water molecules between equatorial and axial positions of the coordination polyhedron.

It was found that in the presence of strongly hydrated lithium ions, the axial positions are predominantly occupied by water molecules; in other cases, by halide ligands. A similar structure is observed in the solid phase. Thus, in the compound $\mathrm{LiCuCl}_{3} \cdot 2 \mathrm{H}_{2} \mathrm{O}$ water molecules in the axial positions of the copper coordination polyhedron are shared by copper and lithium ions. ${ }^{85}$ Correspondingly, lithium ions substantially facilitate dehydration processes that make a significant endothermic contribution to the thermodynamics of laser-induced deposition of copper.

The complexation of copper ions in an aqueous solution with polydentate ligands - EDTA, a tartrate ion, polyols and so on - was considered in numerous works. The equilibrium constants for complexation reactions in these

Table 2. Coordination polyhedron types (geometry of the coordination environment) for the copper ion in copper halide complexes in water and some non-aqueous solvents. ${ }^{23,28,30,31,33,74-84}$

\begin{tabular}{|c|c|c|c|c|c|}
\hline \multirow[t]{2}{*}{ Complex $^{\text {a }}$} & \multicolumn{5}{|l|}{ Solvent } \\
\hline & water & DMSO & DMF & tetrahydrofuran & methanol \\
\hline$\left[\mathrm{Cu}(\text { Solv })_{x}\right]^{2+}$ & Octahedron ${ }^{b}$ & Octahedron or square & Octahedron & Octahedron & Octahedron \\
\hline$\left[\mathrm{CuCl}(\mathrm{Solv})_{x}\right]^{+}$ & Octahedron & The same & Octahedron or square & $"$ & $"$ \\
\hline $\left.\mathrm{CuBr}(\mathrm{Solv})_{x}\right]^{+}$ & $"$ & Octahedron & Octahedron & - & - \\
\hline$\left[\mathrm{CuCl}_{2}(\mathrm{Solv})_{x}\right]$ & $"$ & $"$ & $"$ & Octahedron & Octahedron \\
\hline$\left[\mathrm{CuBr}_{2}(\text { Solv })_{x}\right]$ & $"$ & $"$ & Octahedron or tetrahedron & - & - \\
\hline$\left[\mathrm{CuCl}_{3}(\mathrm{Solv})_{x}\right]^{-}$ & $"$ & Tetrahedron & Tetrahedron & $\begin{array}{l}\text { Tetrahedron/octa- } \\
\text { hedron equilibrium }\end{array}$ & Octahedron \\
\hline$\left[\mathrm{CuBr}_{3}(\mathrm{Solv})_{x}\right]^{-}$ & Tetrahedron & $"$ & $"$ & - & - \\
\hline$\left[\mathrm{CuCl}_{4}(\mathrm{Solv})_{x}\right]^{2-}$ & $\begin{array}{l}\text { Tetrahedron/octa- } \\
\text { hedron equilibrium }\end{array}$ & $"$ & $"$ & Tetrahedron & Octahedron \\
\hline$\left[\mathrm{CuBr}_{4}(\mathrm{Solv})_{x}\right]^{2-}$ & $\begin{array}{l}\text { Square/tetrahedron } \\
\text { equilibrium }\end{array}$ & $"$ & $"$ & - & - \\
\hline
\end{tabular}

a Solv is a solvent. ${ }^{\mathrm{b}}$ The distorted octahedral environment of the copper ion, the coordination number is 6 . 
systems largely depend on the $\mathrm{pH}$ of the medium. It is necessary to take into account both the protonation (deprotonation) of these ligands and the possible forced hydrolysis of copper ions. However, it can be stated that the complexation with these ligands occurs more easily in an alkaline medium. The protonation of the ligand leads to a decrease in the apparent stability constants and a change in the structural parameters of the complex. In this aspect, it is interesting to compare the $\mathrm{Cu}-\mathrm{O}$ distances in squareplanar copper complexes with ethylene glycol and the ethylene glycolate anion: in the solid phase these distance are $2.10 \AA$ for the neutral complex, $1.978-1.986 \AA$ for the monoanion and 1.921-1.931 $\AA$ for the dianion. ${ }^{86}$ In alkaline solutions of polyhydric alcohols, for example glycerol, two basic forms of the complexes corresponding to the biand tridentate coordination of the glycerate $(\mathrm{Gl})$ anion to the copper ion are formed [for glycerol, $\mathrm{CuGl}_{2}(\mathrm{OH})_{2}^{2-}$, $\left.\log K=21.1 \pm 0.1 ; \mathrm{CuGl}_{2}(\mathrm{OH})_{3}^{2-}, \log K=20.2 \pm 0.4\right] .{ }^{87}$ The decrease in the metal-ligand distance is favourable for the electron transfer from the reducing species (ligand) to the copper ion and leads to an increase in the fraction of the bulk nucleation in laser-induced reduction of copper.

An increase in the number of donor groups in the ligand molecule, for example, in hexahydric alcohol - sorbitol (Sorb) - compared with ethylene glycol or glycerol, results in the formation of polynuclear complexes due to different causes, including the conformational flexibility of the ligand. The maximum nuclearity of the complexes with glycerol is three, ${ }^{88}$ whereas the degree of polymerization for sorbitol is substantially higher: the 16-nuclear complex $\mathrm{Li}_{8}\left[\mathrm{Cu}_{16}\left(\mathrm{D}-\mathrm{SorbH}_{4}^{-}\right)_{4}\left(\mathrm{Sorb}-1,2,3,4-\mathrm{H}_{4}^{-}\right)_{4} \cdot 46 \mathrm{H}_{2} \mathrm{O}\right.$ crystallizes from the solution. ${ }^{89}$ Undoubtedly, the reduction of this complex should give rise to polymeric fragments, while polyol chains can serve as anchors for the reduced complex to attach it to the dielectric surface. This is in complete agreement with the experimental data on the topology and electrical conductivity of copper deposits obtained by laserinduced reduction. $47,48,90$

As mentioned above, the use of organic solvents should be favourable for the reduction of copper. However, aqueous solutions undoubtedly have considerable advantages, such as low cost, the ease of regeneration and environmental safety. Therefore, it may be appropriate to look into the possibility of using aqueous-organic mixtures as solvents for LCLD in order to find conditions, under which copper ions in solution are solvated predominantly by organic compounds. Studies of the solvation and complexation of copper ions in mixed aqueous organic solvents are focused mainly on the determination of thermodynamic characteristics of water-mixed solvent transfer processes and stability constants of acido complexes. The data on the structural parameters of solvation or solvation acido complexes are scarce, and the precise determination of these parameters is a virtually unsolvable problem because methods most adequate for this purpose (particularly, EXAFS spectroscopy) are unable to distinguish identical donor atoms in molecules of different solvents. Nevertheless, the results of these studies are of interest for the present review since they provide insight into the prospects for further development of basic research in the field of laser-induced chemical liquid phase deposition of metals aimed at finding approaches to control the ratio between the bulk and surface deposition, as well as between the photochemical and thermochemical components of the process.
Investigations of the thermodynamics of transfer processes demonstrated that the Gibbs free energy of the transfer is positive and negative in the case of weaker and stronger donor organic solvents, respectively, ${ }^{46,90,91}$ compared with water, which is attributed to the difference in the solvation energy of copper ions. Based on the electronic absorption spectroscopy data, Borina ${ }^{92}$ showed that oxygen-containing solvents (weaker $\sigma$-donors than water) preferably occupy axial positions in the copper coordination polyhedron. According to the published data, this rearrangement is a non-monotonic process. Thus, the plot of the spectroscopic properties of solutions versus the composition of the solvent shows distinct inflection points. ${ }^{93,94}$

The precise determination of the composition of the solvation sphere of copper ions in mixed solvents is a difficult task. The compositions of the first solvation sphere of the copper ion were calculated from the electronic absorption spectroscopy data, which is suitable for the determination of the type of the coordination polyhedron, and the IR spectra, from which it is possible to calculate the number of molecules of each solvent. ${ }^{95}$ This approach was applied to investigate solvation processes in $\mathrm{CuX}_{2}-\mathrm{H}_{2} \mathrm{O}-$ Solv systems $\left(\mathrm{X}=\mathrm{Cl}, \mathrm{Br}, 1 / 2 \mathrm{SO}_{4}\right.$; Solv $=\mathrm{DMSO}, \mathrm{DMF}$, DMA). Studies of systems containing DMSO showed that copper ions are solvated mainly by dimethyl sulfoxide throughout the composition range of the solvent (Fig. 6). However, for copper sulfate the percentage of DMSO in the first solvation sphere is higher compared with copper halides, i.e., the interaction with an organic component in the case of copper sulfate is energetically much more favourable.

In copper halide solutions, coordination disproportionation processes take place

$$
\begin{aligned}
& 2 \mathrm{CuCl}_{2}+7 \mathrm{Solv} \longrightarrow\left[\mathrm{Cu}(\text { Solv })_{6}\right]^{2+}+\left[\mathrm{CuCl}_{3}(\text { Solv })\right]^{-}+\mathrm{Cl}^{-} \\
& 2 \mathrm{CuCl}_{2}+6 \mathrm{Solv} \longrightarrow\left[\mathrm{CuCl}(\text { Solv })_{5}\right]^{+}+\left[\mathrm{CuCl}_{3}(\text { Solv })\right]^{-}
\end{aligned}
$$

the former process being dominant in the region with a high water content, whereas the latter being the major one in solutions with a high DMSO content. The formation of tetrahedral structures in a copper chloride solution is

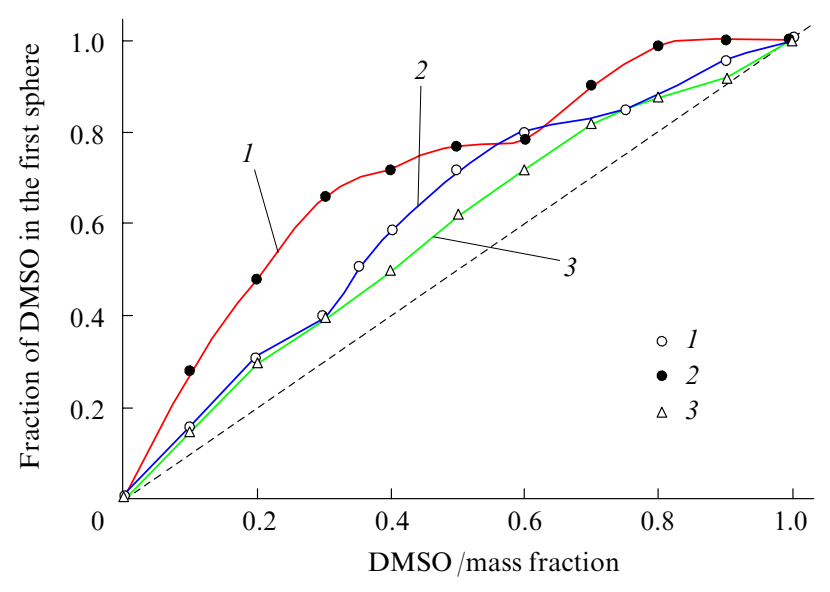

Figure 6. Concentration dependences illustrating the predominant solvation in $\mathrm{CuX}_{2}-\mathrm{H}_{2} \mathrm{O}-\mathrm{DMSO}$ systems. ${ }^{95}$ $\mathrm{X}=1 / 2 \mathrm{SO}_{4}(1), \mathrm{Cl}(2), \mathrm{Br}(3)$. 
observed starting with the 0.5 mole fraction of DMSO, in a copper dibromide solution, with the 0.4 mole fraction. This is indirect evidence that copper dibromide holds promise for the efficient laser-induced deposition of copper from water-DMSO mixtures.

The behaviour of $\mathrm{CuX}_{2}-\mathrm{H}_{2} \mathrm{O}-\mathrm{DMF}$ systems $(\mathrm{X}=\mathrm{Cl}$, $\left.\mathrm{Br}, 1 / 2 \mathrm{SO}_{4}\right)$ is similar to that of the above-considered systems. The total solvation number of copper halides is smaller than that of copper sulfate due to the enhancement of acido complexation. In $\mathrm{CuX}_{2}-\mathrm{H}_{2} \mathrm{O}-\mathrm{DMA}$ systems $(\mathrm{X}=\mathrm{Cl}, \mathrm{Br})$, the coordination disproportionation is pronounced. Of all the studied systems, water-DMA mixtures produce tetrachlorocuprate. Therefore, this mixed solvent is most promising also for laser-induced deposition of copper. The above-considered results can, in part, account for the higher efficiency of laser-induced deposition from copper chloride solutions. ${ }^{34}$

In the discussion of thermally induced laser processes, the photochemical component cannot be completely ignored because, as mentioned above, this component can also make a considerable contribution to the overall process. ${ }^{53,54}$ Let us note that many soluble copper compounds (as well as compounds of silver, gold and many other metals) were shown to be prone to photochemical reduction. ${ }^{96-99}$ On the whole, the photochemistry of copper(I) and copper(II) complexes is determined by the photochemical activity of their excited states associated with the charge transfer processes - the metal-to-ligand charge transfer (MLCT) and the ligand-to-metal charge transfer (LMCT) - to the solvent, as well as with the intraligand excitation. ${ }^{100,101}$ Many redox reactions can be considered as a sequence of deactivation processes of these excited states. It should be noted that the fully occupied $d$ orbitals in copper(I) coordination compounds prevent $\mathrm{d}-\mathrm{d}$ electron transitions within the metal centre and, as a rule, the MLCT excited states are photochemically active. On the contrary, these transitions are characteristic of copper(II) complexes with the $\mathrm{d}^{9}$ electronic configuration and correspond to absorption bands in the long-wavelength (red) spectral region and in the near-IR range, while the LMCT excited states are usually photochemically active. ${ }^{100,101}$

It should be emphasized that copper(I) complexes are more prone to photooxidation and thermally induced reduction. In particular, this can be attributed to the fact that high-lying MLCT excited states are difficult to access. Meanwhile, numerous examples of the photochemical reduction of copper(II) complexes and the photochemical deposition of metallic copper from copper(II) salt solutions were reported in the literature. For example, Ouchi et al. ${ }^{102}$ showed that the photochemical deposition of elemental copper can be performed using a solution of copper(II) acetylacetonate in isopropyl alcohol via a two-step process involving the photoreduction of copper(II) acetylacetonate to copper(I) acetylacetonate followed by thermal decomposition to elemental copper. Barta et al. ${ }^{103}$ demonstrated that the photolysis of dilute solutions of copper(II) sulfate in water also gives rise to elemental copper particles by a similar mechanism. The number of studies dealing with photochemical deposition of copper from copper(II) salt solutions is much smaller compared with investigations on laser-induced deposition. The systematic analysis of the published data on the photochemistry of copper(II) complexes is necessary to perform in order to optimize laserinduced chemical liquid phase deposition of copper. ${ }^{104-106}$
The electronic absorption spectra of copper(II) complexes show intense LMCT bands in the visible UV region and, as mentioned above, bands in the long-wavelength spectral region and the near-IR range assigned to $\mathrm{d}-\mathrm{d}$ transitions. ${ }^{107-110}$ The excitation of copper complexes to the $\mathrm{d}-\mathrm{d}$ states does not induce the photoreaction, ${ }^{100,108}$ whereas the LMCT excited states are dissociative and lead to the reduction of copper(II) to copper(I) and oxidation of ligands. ${ }^{107,108}$ If the spin-allowed intraligand excited state of $\mathrm{Cu}^{\mathrm{II}} \mathrm{L}^{*}$, which is also photoactive for copper(II) complexes, is occupied first, the very rapid internal conversion to the photoactive LMCT excited state followed by the formation of photoreduction products of copper(II) usually take place. Three alternative pathways of photochemical redox reactions of copper(II) complexes were proposed: ${ }^{100}$

$$
\begin{aligned}
& \text { 1) } \mathrm{Cu}^{\mathrm{II}} \mathrm{LSolv} \stackrel{h v}{\longrightarrow} \mathrm{Cu}^{\mathrm{I} S o l v}+\mathrm{L}_{\mathrm{ox}} \\
& \mathrm{Cu}^{\mathrm{II}} \mathrm{L}_{2} \mathrm{Solv} \stackrel{h v}{\longrightarrow} \mathrm{Cu}^{\mathrm{I}} \mathrm{L}_{2}+\mathrm{Solv}_{\mathrm{ox}} \\
& \mathrm{Cu}^{\mathrm{I}} \mathrm{LL}_{2}^{\prime} \stackrel{h v}{\longrightarrow} \mathrm{Cu}^{\mathrm{I}} \mathrm{LL}^{\prime}+\mathrm{L}_{\mathrm{ox}} \\
& \mathrm{Cu}^{\mathrm{I}} \mathrm{L}_{2} \stackrel{h v}{\longrightarrow} \mathrm{Cu}^{\mathrm{I}} \mathrm{L}+\mathrm{L}_{\mathrm{ox}} \\
& \mathrm{Cu}^{\mathrm{I}} \mathrm{L} \longrightarrow \mathrm{Cu}^{0}+\mathrm{L}_{\mathrm{ox}} \\
& \text { 2) } \mathrm{Cu}^{\mathrm{II} L} \stackrel{h v}{\longrightarrow} \mathrm{Cu}^{\mathrm{III}} \cdots \mathrm{L}^{-} \\
& \text {3) } \mathrm{Cu}^{\mathrm{II}} \mathrm{L} \stackrel{h v}{\longrightarrow} \mathrm{Cu}^{\mathrm{I}} \cdots \mathrm{L}_{\mathrm{ox}} \\
& \mathrm{Cu}^{\mathrm{I}} \cdots \mathrm{L}_{\mathrm{ox}} \longrightarrow \mathrm{Cu}^{\mathrm{II}}+\mathrm{L} \\
& \mathrm{Cu}^{\mathrm{II}} \mathrm{L}_{2}+\mathrm{Solv}^{*} \longrightarrow\left[\mathrm{Cu}^{\mathrm{II}} \mathrm{L}_{2} \cdots \mathrm{Solv}^{*}\right] \longrightarrow \mathrm{Cu}^{\mathrm{I} L}+\mathrm{L}_{\mathrm{ox}}+\mathrm{Solv} \\
& 2 \mathrm{Cu}^{\mathrm{I} L} \longrightarrow \mathrm{Cu}^{\mathrm{II}} \mathrm{L}_{2}+\mathrm{Cu}^{0} \\
& \mathrm{Cu}^{\mathrm{I} L}+\mathrm{L}_{\mathrm{ox}} \longrightarrow \mathrm{Cu}^{\mathrm{II}} \mathrm{L}_{2} \\
& \mathrm{Cu}^{\mathrm{II} L}+\mathrm{Solv}^{*} \longrightarrow \mathrm{Cu}^{\mathrm{I}} \mathrm{L}+\mathrm{Solv}^{+}
\end{aligned}
$$

where Solv is the solvent, $\mathrm{L}$ and $\mathrm{L}^{\prime}$ are ligands other than the solvent, $\mathrm{L}_{\mathrm{ox}}, \mathrm{L}_{\mathrm{ox}}^{\prime}$ and $\mathrm{Solv}_{\mathrm{ox}}$ are oxidized forms of the ligands and the solvent, respectively.

It should be noted that the photoreduction exhibits a low quantum yield because the majority of LMCT-excited copper(II) complexes relax to the ground electronic state, and only a small part of these complexes dissociates to form a copper(I) compound. ${ }^{104,108,109}$

The dynamics of excited electronic states of copper complexes with inorganic ligands, for example, chloro complexes of copper(II) in methanol and acetonitrile, ${ }^{104,108}$ is analogous to that of copper(II) complexes with organic ligands, for example, well-studied blue copper proteins, ${ }^{110-116}$ which are characterized by the relaxation from the LMCT excited state to the ground state within 1 ps via low-lying $\mathrm{d}-\mathrm{d}$ excited states. The LMCT excited states of copper(II) complexes with inorganic ligands also have lifetimes of about hundreds of femtoseconds. The major part of LMCT excited states of chloride complexes relaxes to the ground electronic state in a stepwise manner through low-lying $\mathrm{d}-\mathrm{d}$ states, whereas an insignificant part of excited complexes dissociates to form copper(I) complexes and oxidized ligands. ${ }^{108,109,117-129}$ Besides, the $\mathrm{d}-\mathrm{d}$ states in some copper(II) complexes, for example, in $\left[\mathrm{CuCl}_{4}\right]^{2-}$ in acetonitrile, have much longer lifetimes (several picoseconds), ${ }^{108}$ which may retard the reduction of copper in the LCLD process.

In most of studies concerned with the dynamics of excited electronic states, the focus was placed on photophysical processes. There are also extensive data on the 
analysis of stable products of photochemical reactions and the determination of the quantum yields of their formation without consideration of superfast processes. For many copper(II) complexes, ${ }^{108,109,117-130}$ the LMCT excitation was shown to result in the reduction of copper(II) to copper(I) and oxidation of the ligand. Consequently, in order to accomplish the photochemical liquid phase deposition of copper, it is necessary to use a copper(II) compound such that exhibits high quantum yield of photoreduction of copper(II) to copper(I), and the resulting copper(I) complex should be rather easily decomposed either on heating or under light irradiation. Thus, da Silva and David ${ }^{130}$ demonstrated that the LMCT excitation of the solvated copper(II) complex in methanol, $\left[\mathrm{Cu}(\mathrm{MeOH})_{6}\right]^{2+}$, by UV light $(200-250 \mathrm{~nm})$ affords the solvated copper(I) complex $\left[\mathrm{Cu}(\mathrm{MeOH})_{5}\right]^{+}$and $\left[\mathrm{CH}_{3} \mathrm{OH}\right]^{+}$ followed by the transformation of the latter cation into the $\mathrm{CH}_{3} \mathrm{O}^{-}$radical and finally to formaldehyde. The study of the photochemistry of chloride and bromide complexes of copper(II) $\left(\left[\mathrm{Cu}(\mathrm{MeOH})_{6-n} \mathrm{X}_{n}\right]^{2-n}, \quad \mathrm{X}=\mathrm{Cl}^{-}, \mathrm{Br}^{-} ; n=\right.$ $1-4)$ in methanol showed ${ }^{117}$ that the UV photolysis of these complexes leads to the copper-halogen bond cleavage to form a copper(I) complex and a halogen atom, which oxidizes methanol to formaldehyde. It was noted that complexes with a different number of halide ligands exhibit different quantum yields for photoreduction of copper(II). Besides, it should be emphasized that the quantum yield of photoreduction of all chloride complexes of copper(II) is $<10 \%$, whereas some bromide complexes of copper(II) have the quantum yield of photoreduction of $100 \%$. Chloride complexes of copper(II) in acetonitrile are also characterized by low quantum yields of the copper(I) formation $(0 \%-13 \%) .{ }^{118}$
The photochemistry of copper(II) complexes with organic nitrogen-, oxygen-, sulfur- and selenium-containing ligands has been extensively studied. It was demonstrated ${ }^{119-129}$ that the LMCT excitation of these complexes also results in the reduction of copper and oxidation of the ligand. In most cases, the quantum yield of photoreduction of copper(II) to copper(I) is $<10 \%$ and it substantially decreases with an increase in the light excitation wavelength. On the whole, the quantum yield of copper(I) is higher for nitrogen- and oxygen-containing ligands compared with sulfur- and selenium-containing ligands. As in the case of inorganic copper(II) complexes, the low quantum yield of photoreduction is attributed to the efficient and rapid (within $200 \mathrm{fs}$ ) internal conversion of the LMCT excited state. ${ }^{109}$ Copper(II) complexes hold promise for laser-induced deposition of elemental copper. In this case, the copper(I) complex disproportionates to form copper(0). For example, copper(I) acetate generated from copper(II) acetate was shown to be unstable, resulting in the disproportionation to form copper(II) and copper(0) ${ }^{119}$

$$
\begin{aligned}
& \mathrm{Cu}(\mathrm{OAc})_{2} \stackrel{h v}{\longrightarrow} \mathrm{CuOAc}+{ }^{\circ} \mathrm{OAc} \\
& 2 \mathrm{CuOAc} \longrightarrow \mathrm{Cu}^{0}+\mathrm{Cu}(\mathrm{OAc})_{2}
\end{aligned}
$$

The data on the photochemical processes in copper-containing solutions are briefly summarized in Table 3 .

The above-considered data suggest that solutions containing bromide, acetate and oxalate complexes of copper(II) are most suitable for optimization of laser-induced deposition of copper.

\begin{tabular}{|c|c|c|c|c|c|}
\hline \multicolumn{2}{|l|}{ Compound } & \multirow[t]{2}{*}{ Solvent } & \multirow{2}{*}{$\begin{array}{l}\text { Wavelength } \\
/ \mathrm{nm}\end{array}$} & \multirow{2}{*}{$\begin{array}{l}\text { Quantum yield } \\
\text { of copper(I) }(\%)\end{array}$} & \multirow[t]{2}{*}{ Ref. } \\
\hline formula & $\mathrm{L}$ & & & & \\
\hline \multirow[t]{2}{*}[\mathrm{CuL}_{6}]{$^{2+}$} & $\mathrm{MeOH}$ & Methanol & 250 & 1.8 & 129 \\
\hline & $\mathrm{MeOH}$ & $"$ & 300 & 0.4 & 129 \\
\hline \multirow[t]{2}{*}[\mathrm{Cu}(\mathrm{MeOH})_{6-n}\mathrm{L}_{n}]{$^{2-n}$} & $\mathrm{Cl}^{-}$ & $"$ & 300 & $2-8$ & 116 \\
\hline & $\mathrm{Br}^{-}$ & $"$ & 250 & $1.4-140$ & 116 \\
\hline$\left[\mathrm{Cu}(\mathrm{MeCN})_{4-n} \mathrm{~L}_{n}\right]^{2-n}$ & $\mathrm{Cl}^{-}$ & Acetonitrile & 471 & $0-13$ & 117 \\
\hline \multirow[t]{19}{*}{$\mathrm{CuL}_{2}$} & Acetate & Methanol & 308 & 0.8 & 118 \\
\hline & $"$ & Isopropyl alcohol & 308 & 2.5 & 118 \\
\hline & Trifluoroacetate & Methanol & 248 & 16 & 118 \\
\hline & Pentafluorobutyrate & $"$ & 248 & 11 & 118 \\
\hline & Heptafluoropropionate & $"$ & 248 & 10 & 118 \\
\hline & Diethyldiselenocarbamate & Chloroform & 254 & 3.0 & 119 \\
\hline & " & " & 313 & 0.9 & 119 \\
\hline & $"$ & " & 436 & 0.3 & 119 \\
\hline & $"$ & Dichloromethane & 254 & 1.3 & 119 \\
\hline & $"$ & " & 313 & 0.5 & 119 \\
\hline & $"$ & $"$ & 436 & 0.1 & 119 \\
\hline & $"$ & Toluene & 436 & 0.04 & 119 \\
\hline & Diethyldithiocarbamate & Tetrachloromethane & 313 & 3.1 & 120 \\
\hline & $"$ & $"$ & 436 & 3.7 & 120 \\
\hline & $"$ & $"$ & 578 & 0.024 & 120 \\
\hline & $"$ & Chloroform & 313 & 2.8 & 120 \\
\hline & $"$ & " & 436 & 3.7 & 120 \\
\hline & $"$ & $"$ & 578 & 0.023 & 120 \\
\hline & $"$ & Toluene & 313 & 2.6 & 120 \\
\hline
\end{tabular}

Table 3. Quantum yields of photoreduction of copper(II) to copper(I) in different solutions. 
Table 3 (continued).

\begin{tabular}{|c|c|c|c|c|c|}
\hline \multicolumn{2}{|l|}{ Compound } & \multirow[t]{2}{*}{ Solvent } & \multirow{2}{*}{$\begin{array}{l}\text { Wavelength } \\
/ \mathrm{nm}\end{array}$} & \multirow{2}{*}{$\begin{array}{l}\text { Quantum yield } \\
\text { of copper(I) }(\%)\end{array}$} & \multirow[t]{2}{*}{ Ref } \\
\hline formula & $\mathrm{L}$ & & & & \\
\hline \multirow[t]{16}{*}{$\mathrm{CuL}_{2}$} & Diethyldithiocarbamate & Toluene & 436 & 3.3 & 120 \\
\hline & $"$ & $"$ & 578 & 0.022 & 120 \\
\hline & $"$ & Acetone & 313 & 3.6 & 120 \\
\hline & $"$ & $"$ & 436 & 3.4 & 120 \\
\hline & $"$ & $"$ & 578 & 0.027 & 120 \\
\hline & Diisopropyl dithiophosphate & Tetrachloromethane & 313 & 3.8 & 120 \\
\hline & $"$ & $"$ & 436 & 4.2 & 120 \\
\hline & $"$ & $"$ & 578 & 0.03 & 120 \\
\hline & $"$ & Chloroform & 313 & 4.6 & 120 \\
\hline & $"$ & $"$ & 436 & 3.2 & 120 \\
\hline & $"$ & $"$ & 578 & 0.036 & 120 \\
\hline & $"$ & $"$ & 436 & 3.7 & 120 \\
\hline & $"$ & $"$ & 578 & 0.031 & 120 \\
\hline & $"$ & Acetone & 313 & 4.0 & 120 \\
\hline & $"$ & $"$ & 436 & 3.8 & 120 \\
\hline & $"$ & $"$ & 578 & 0.036 & 120 \\
\hline \multirow{2}{*}{$\begin{array}{l}\mathrm{CuLX}(\mathrm{X}=\mathrm{Cl}, \mathrm{Br} \\
\left.\mathrm{ClO}_{4}, \mathrm{NO}_{3}\right)\end{array}$} & \multirow[t]{2}{*}{ Diethyldithiocarbamate } & Isopropyl alcohol & 406 & 0.1 & 121 \\
\hline & & Ethanol & 406 & 0.5 & 121 \\
\hline $\mathrm{CuL}_{2}$ & Oxalate & Water & 313 & 43 & 122 \\
\hline \multirow[t]{3}{*}{$\mathrm{CuL}^{+}$} & $"$ & $"$ & 313 & 42 & 122 \\
\hline & Succinate & $"$ & 313 & 10 & 122 \\
\hline & Maleate & $"$ & 313 & 0.8 & 122 \\
\hline \multirow[t]{2}{*}{$\mathrm{CuL}_{2}$} & Alanine & $"$ & 313 & 6.4 & 123 \\
\hline & $"$ & $"$ & 280 & 8.7 & 123 \\
\hline \multirow[t]{2}{*}{$\mathrm{CuL}^{+}$} & $"$ & $"$ & 313 & 9.4 & 123 \\
\hline & $"$ & $"$ & 280 & 9.4 & 123 \\
\hline \multirow{4}{*}{$\mathrm{CuL}_{2}$} & L-Asparaginate & $"$ & 310 & 6.3 & 124 \\
\hline & L-Histidine & $"$ & 310 & 0.1 & 124 \\
\hline & Glycine & $"$ & 310 & 2.5 & 124 \\
\hline & 3,5-Dipropyl salicylate & Acetonitrile & 436 & 0.28 & 125 \\
\hline
\end{tabular}

\section{IV.2. Dielectric surface properties}

While not rejecting the contribution of the bulk nucleation mechanism, it is necessary to investigate in more detail the effect of the material of the metallized surface on the laser deposition of metal. The key issue in this process is the formation of an activated centre on the dielectric substrate. Otherwise, the crystallization giving a flocculent precipitate will occur in the bulk of the solution via the nucleation mechanism, resulting in poor adhesion of the deposit to the dielectric surface.

The influence of the properties of the substrate on the one-step laser-induced deposition is almost unknown. The pioneering work ${ }^{6}$ in this field showed that the one-step laser-induced deposition is much more efficient on nonsingle-phase composite surfaces, including those formed by highly strong dielectrics (Fig. 7). Besides, the deposition rate strongly depends on the temperature conditions for the irradiation of the surface associated with the nonuniform distribution of laser radiation power density with an increase in the distance from the beam focus (Fig. 8).

The influence of the temperature conditions of laser deposition on the morphology of deposits has been observed earlier. ${ }^{74,75}$ Temperature changes during laser deposition of metal thin films were studied ${ }^{75}$ by the interferometric method based on the difference in the optical thickness of the glass surface during heating. The layout of measurements for the deposition of a metal film onto the oxide glass surface is based on the fact that a $\mathrm{He}-\mathrm{Ne}$ laser beam (serving as a probe) is focused onto the opposite side of the substrate using a continuous-wave Ar laser, and the temperature changes are recorded.

An analysis of the temperature distribution in the zone irradiated with a laser beam showed that the temperature at the focused laser spot reaches $\sim 1000{ }^{\circ} \mathrm{C}$, resulting in the activation of the dielectric surface in the adjoining area; however, chemical reactions do not proceed at the focus, and the processes that take place are the laser ablation of the substrate surface and copper nucleates, which can be generated from the solution. The temperature rapidly drops outside the focused laser spot.

Four morphological zones of the solidification of copper structures were distinguished on the surface of glass-like silicon oxide during laser melting, which differ in the structure and the mechanism of the formation of a crystalline phase. ${ }^{74}$ Besides, zoning of the copper deposit was 

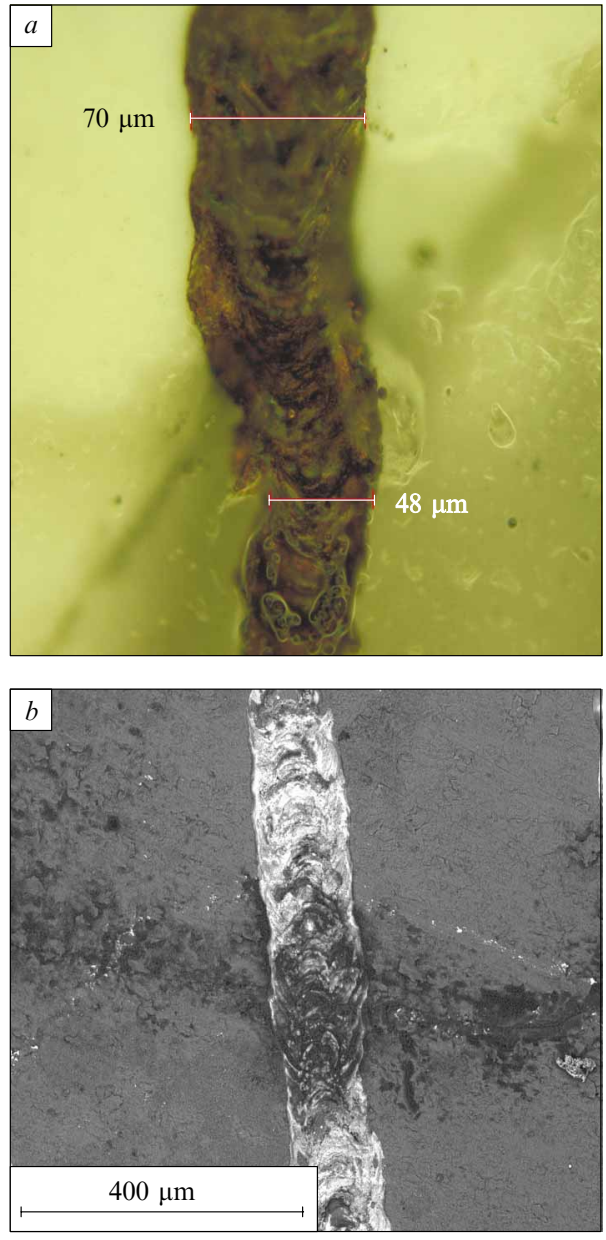

Figure 7. Optical $(a)$ and electron $(b)$ micrographs demonstrating the difference in the morphology of copper deposits poduced by laser-induced deposition in going from a single-phase area of the $\mathrm{SiO}_{2}$ surface (dark regions of the substrate) to a two-phase $\mathrm{SiO}_{2}+\mathrm{Al}_{2} \mathrm{O}_{3}$ area (lighter regions of the substrate).

studied depending on the distance from the focused laser spot. ${ }^{8}$

The above-considered data are as yet insufficient to provide systematic view of the influence of the dielectric surface properties on the results of laser-induced copper plating. However, these data show that the structure and type of substrate defects, which are initially present and are produced by laser irradiation, are key factors determining the deposition rate. The class of dielectrics, which can be metallized in local areas by laser ablation, can be extended. Apart from oxide materials, polymer surfaces can be activated by laser irradiation. ${ }^{132}$ In this case, the deposition of metal on the surface of free carbon, which is produced by laser ablation of a polymeric material, is the most probable process. Here, one can also perceive the appearance of phase boundaries responsible for a considerable increase in the number of activation centres on the surface. ${ }^{6}$ The aboveconsidered studies demonstrated that a non-single phase state plays a greater role in the formation of active centres on the dielectric surface than the nature of these phases. It should be noted that the statistics of such studies is poor
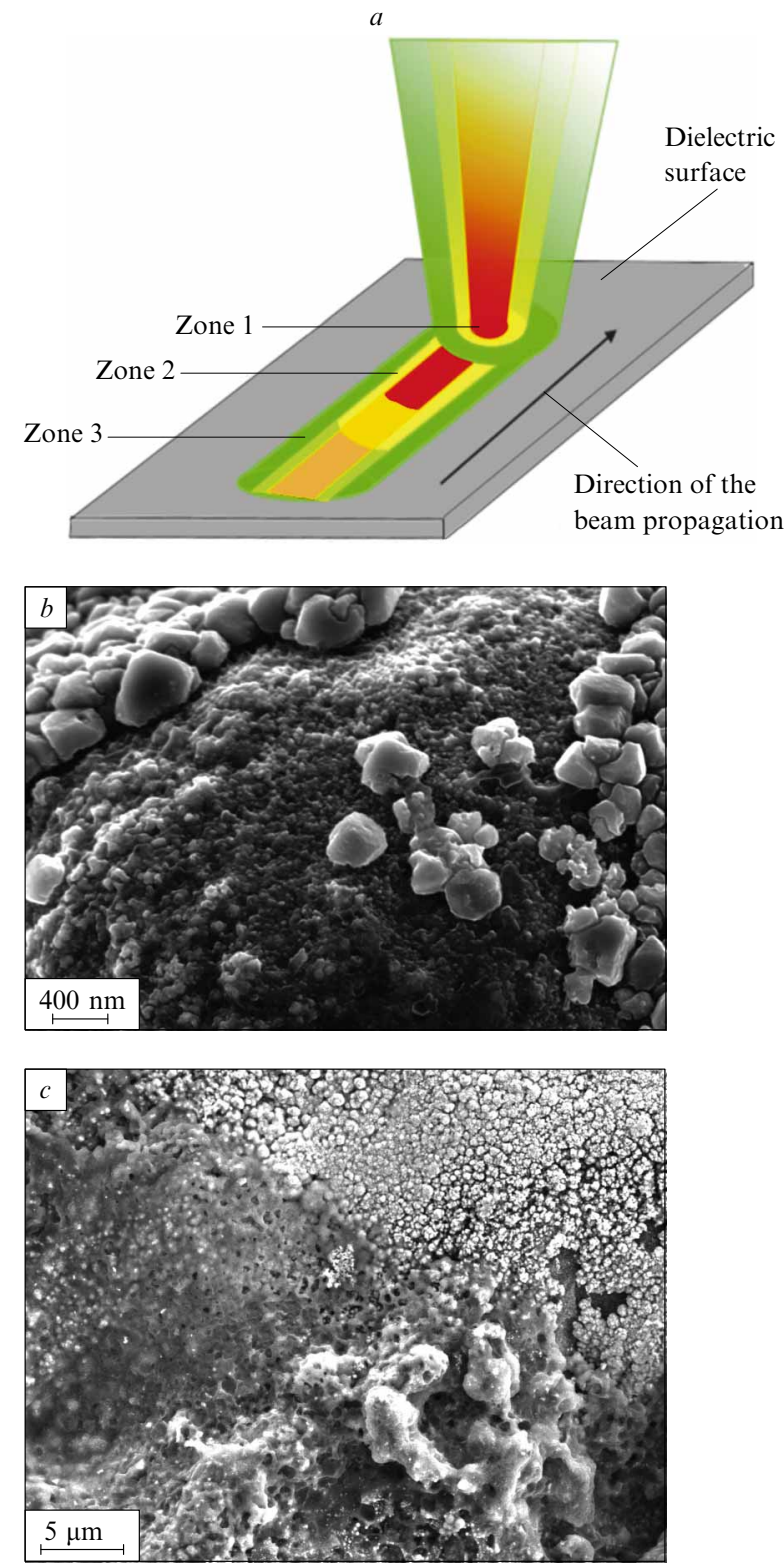

Figure 8. Model of temperature zones on the dielectric surface produced by the moving laser beam $(a)$ and illustrations of the copper deposition zoning produced by the laser scanning of the surface of the composite material Sitall ST-50 $\left(\mathrm{SiO}_{2}+\mathrm{Al}_{2} \mathrm{O}_{3}\right)$ using glycerol $(b)$ and sorbitol $(c)$ as the reducing agents. ${ }^{131}$

and more extensive research is required in order to develop the first model of the process.

$$
* \quad * \quad *
$$

The laser-induced deposition of metals holds promise in different fields, such as microelectronics, micromechanics, the design of various sensors and detectors, as well as catalysts for the selective organic synthesis. More and more researchers employ this method to solve scientific and technical problems, the number of deposited metals is increased and the range of materials used for these purposes is extended. The challenge ahead is the design of flexible composite materials. 
The state of the art of research in this field can be characterized as the stage of primary accumulation of basic knowledge. Therefore, a comprehensive scientific model of the process has not been formulated as yet. Nevertheless, taking into account a keen interest by numerous research groups in this method, it is hoped that this stage of investigations will be successfully completed and investigations on the laser-induced deposition of copper will promote the development of this method.

This review has been written with the financial support of the Saint Petersburg State University (measure 2, Project 12.38.219.2015) and the Russian Foundation for Basic Research (Projects 14-03-01003 and 15-03-05139). A S Mereshchenko and M S Panov thank the Saint Petersburg State University for financial support (Projects 12.50.1562.2013 and 12.50.1189.2014).

\section{References}

1. V A Kochemirovsky, L G Menchikov, S V Safonov, M D Bal'makov, I I Tumkin, Yu S Tver'yanovich Russ. Chem. Rev. 80869 (2011)

2. H Moilanen, J Remes, S Leppavuori Phys. Scr. 69237 (1997)

3. T Szorenyi, Z Kantor, Z Toth, P Heszler Appl. Surf. Sci. 138 $275(1999)$

4. Z Kantor, Z Toth, T Szorenyi Appl. Phys. Lett. 643506 (1994)

5. H G Muller, G Heinrich Appl. Phys. Lett. 56904 (1990)

6. I I Tumkin, V A Kochemirovsky, M D Bal'makov, S V Safonov, E S Zhigley, L S Logunov, E V Shishkova Surf. Coat. Technol. 264187 (2014)

7. V A Kochemirovsky, L S Logunov, S V Safonov, I I Tumkin, Yu S Tver'yanovich, L G Menchikov Appl. Surf. Sci. 25955 (2012)

8. V A Kochemirovsky, S V Safonov, M K Strukov, I I Tumkin, L S Logunov, L G Menchikov Glass Phys. Chem. 39403 (2013)

9. J H G Ng, M P Y Desmulliez, A McCarthy, H Suyal, K A Prior, D P Hand, in DTIP 2008: Symposium on Desing, Test, Integration and Packaging of MEMS/MOEMS, Nise, France, 2008 p. 360

10. K Kordas, J Bekesi, R Vajtai, L Nanai, S Leppavuori, A Uusimaki, K Bali, T F George, G Galbacs, F Ignacz, P Moilanen Appl. Surf. Sci. 172178 (2001)

11. G A Shafeev Adv. Mater. Opt. Electron. 2183 (1993)

12. K Kordas, J Remes, S Leppavuori, L Nanai Appl. Surf. Sci. $17893(2001)$

13. Yu S Tver'yanovich, V A Kochemirovsky, A A Man'shina, A V Povolotskii, A V Povolotskaya, S V Safonov, I I Tumkin Lazerno-Indutsirovannoe Osazhdenie Zolota i Medi iz Rastvorov (Laser-induced Deposition of Gold and Copper from Solutions) (St Petersburg: A S Pushkin Leningrad State University, 2010)

14. H Yokoyama, S Kishida, K Washio Appl. Phys. Lett. 44755 (1984)

15. F Kiriakidou Catal. Today 54119 (1999)

16. J Zhu Curr. Opin. Colloid Interface Sci. 14260 (2009)

17. V A Kochemirovsky, L G Menchikov, I I Tumkin, L S Logunov, S V Safonov Quantum Electron. 42693 (2012)

18. Yu S Tver'yanovich, A G Kuzmin, L G Menchikov, V A Kochemirovsky, S V Safonov, I I Tumkin, A V Povolotsky, A A Manshina Mendeleev Commun. 2134 (2011)

19. X C Wang, H Y Zheng, G C Lim Appl. Surf. Sci. 200165 (2002)

20. G A Shafeev Kvant. Elektron. 241137 (1997) a

21. K Kordas, K Bali, S Leppavuori, A Uusimaki, L Nanai Appl. Surf. Sci. 154399 (2000)
22. J G Liu, C H Chen, J S Zheng, J Y Huang Appl. Surf. Sci. 245155 (2005)

23. K Kordas Acta Univ. Oulu 168 (2002)

24. M A Kapitsa Tekhnol. Elektron. Prom-sti (6) 35 (2005)

25. V A Kochemirovsky, S A Fateev, L S Logunov, I I Tumkin, S V Safonov Int. J. Electrochem. Sci. 9644 (2014)

26. V A Kochemirovsky, E M Khairullina, S V Safonov, L S Logunov, I I Tumkin, L G Menchikov Appl. Surf. Sci. 280494 (2013)

27. V A Kochemirovsky, E M Khairullina, S V Safonov, L S Logunov, I I Tumkin, L G Menchikov Russ. Chem. Bull. 621570 (2013) [Izv. Akad. Nauk, Ser. Khim. 1570 (2013)]

28. W C Griffin J. Soc. Cosmet. Chem. 1311 (1949)

29. V A Kochemirovsky, S V Safonov, I I Tumkin, I A Balova, Yu S Tver'yanovich Vestn. SPbGU, Ser. Fiz. Khim. (2) 77 (2012)

30. V V Sviridov, T N Vorob'eva, T V Gaevskaya, L I Stepanov Khimicheskoe Osazhdenie Metallov iz Vodnykh Rastvorov (Chemical Deposition of Metals from Aqueous Solutions) (Minsk: Izd. Universitetskoe, 1987)

31. N F Melashchenko Gal'vanicheskie Pokrytiya Dielektrikov (Galvanic Coating of Dielectrics) (Minsk: Izd. 'Belarus', 1987)

32. M Ramasubramanian, B N Popov, R E White, K S Chen J. Appl. Electrochem. 28737 (1998)

33. V A Kochemirovsky, S V Safonov, I I Tumkin, Yu S Tver'yanovich, I A Balova, L G Menchikov Russ. Chem. Bull. 601564 (2011) [Izv. Akad. Nauk, Ser. Khim. 60 1540 (2011)]

34. A Manshina, A Povolotskiy, T Ivanova, Yu Tver'yanovich, S P Tunik, D Kim, M Kim, S C Kwon Appl. Phys. A 89755 (2007)

35. S Ahrland, B Tagesson Acta Chem. Scand. 31615 (1977)

36. K M Vansovskaya Metallicheskie Pokrytiya, Nanesennye Khimicheskim Sposobom (Chemical Deposited Metal Coatings) (Leningrad: Mashinostroenie, 1985)

37. T P Petrova Soros. Obrazov. Zh. 6 (11) 57 (2000) b

38. R J Von Gutfeld, E E Tynan, R L Melcher, S E Blum Appl. Phys. Lett. 35651 (1979)

39. R E Acosta, L T Romankiw, R J Von Gutfeld Thin Solid Films 95131 (1982)

40. R J Von Gutfeld, K G Sheppard J. Res. Develop. 42639 (1998)

41. L Nanai, K Kordas, S Leppävuori, T F George, in Modern Topics in Chemical Physics (Eds T F George, X Sun G P Zhang) (Trivandrum, India: Research Signpost, 2002) p. 287

42. M R Bruk, G A Shafeev, V S Petrosyan, V P Dyadchenko, K I Grandberg, E I Smyslova Kvant. Elektron. 181088 $(1991)^{\mathrm{a}}$

43. F V Bunkin, K I Grandberg, B S Luk'yanchuk, E G Perevalova, G A Shafeev Kvant. Elektron. 131320 $(1986)^{\mathrm{a}}$

44. D Bauerle, in Laser Processing and Chemistry (Berlin, Heidelberg: Springer-Verlag, 2000) p. 781

45. V A Kochemirovsky, L G Menchikov, A G Kuz'min, S V Safonov, I I Tumkin, Yu S Tver'yanovich Russ. Chem. Bull., 611041 (2012) [Izv. Akad. Nauk, Ser. Khim. 611035 (2012)]

46. P Singh, I D McLeod, A J Parker J. Solut. Chem. 11495 (1982)

47. M Elleb, J Meullemeestre, M J Schwing-Weill, F Vierling Inorg. Chem. 192699 (1980)

48. P G David Polyhedron 4437 (1985)

49. N V Karlov, N A Kirichenko, B S Luk'yanchuk Russ. Chem. Rev. 62203 (1993)

50. N V Karlov, N A Kirichenko, B S Luk'yanchuk Lazernaya Termokhimiya (Laser Termochemistry) (Moscow: Nauka, 1992) 
51. J Ohara, M Nagakubo, N Kawahara, T Hattori, in Proceedings of the IEEE Tenth Annual International Workshop on Micro ElectroMechanical Systems, New York, 1997 p. 175

52. M D Bal'makov Fiz. Khim. Stekla 15293 (1989) ${ }^{\mathrm{c}}$

53. I I Roslov, Candidate Thesis in Chemical Sciences, Herzen State Pedagogical University of Russia, St Petersburg, 2010

54. T B Boitsova, Candidate Thesis in Chemical Sciences, Herzen State Pedagogical University of Russia, St Petersburg, 2010

55. I E Tamm Zh. Eksp. Teor. Fiz. 334 (1933) d

56. P P Konorov, A M Yafyasov Fizika Poverkhnosti Poluprovodnikovykh Elektrodov (The Physics of the Surface of Semiconductor Electrodes) (St Petersburg: St Petersburg State University, 2003)

57. G A Shafeev, S M Pimenov, E N Loubnin Appl. Surf. Sci. 86 392 (1995)

58. A A Lyanin, M S Nunuparov, A V Simakin, G A Shafeev Adv. Mater. Opt. Electron. 5299 (1995)

59. V A Ageev, A F Bokhonov, V V Zhukovskii, A A Yankovskii J. Appl. Spectrosc. 64683 (1997)

60. A Kruusing Opt. Lasers Eng. 41329 (2004)

61. H Esrom MRS Symp. Proc. 204457 (1991)

62. H Esrom, J-Y Zhang, A J Pedraza MRS Symp. Proc. 236383 (1992)

63. A J Pedraza, M J Godbole, M J DeSilva, D H Lowndes MRS Symp. Proc. 285203 (1993)

64. J Bjerrum Metal Ammine Formation in Aqueous Solution: Theory of the Reversible Step Reactions (Copenhagen, Denmark: P Haase and Son, 1941)

65. Y Marcus J. Chem. Soc., Faraday Trans. 872995 (1991)

66. J B Sharkey, S Z Lewin Thermochim. Acta 3189 (1972)

67. A Pasquarello, I Petri, P S Salmon, O Parisel, R Car, E Toth, D H Powell, H E Fischer, L Helm, A E Merbach Science 291 856 (2001)

68. I Persson, P Persson, M Sandstrom, A Ullström J. Chem. Soc., Dalton Trans. 1256 (2002)

69. Y Inada, H Hayashi, K Sugimoto, S Funahashi J. Phys. Chem. A 1031401 (1999)

70. R G Pearson J. Chem. Ed. 45643 (1968)

71. Novyi Spravochnik Khimika i Tekhnologa. Khimicheskoe Ravnovesie. Svoistva Rastvorov (New Handbook for Chemist and Engineer. Chemical Equilibrium. Properties of Solutions) (Ed. S A Simanova) (St Petersburg: Mir i Sem'ya, 2004)

72. J Fan, X S J Wang Electroanalysis 131115 (2001)

73. F Shakerizadeh-Shirazi, B Hemmateenejad, A M Mehranpour Anal. Methods 5891 (2013)

74. R Zhong, A Kulovits, J M K Wiezorek, J P Leonard Appl. Surf. Sci. 256105 (2009)

75. E A Morozova, G A Shafeev, M Wautelet Measure Sci. Technol. 3302 (1992)

76. M Elleb, J Meullemeestre, M-J Schwing-Weill, F Vierling Inorg. Chem. 211477 (1982)

77. S Amuli, J Meullemeestre, M J Schwing, F Vierling Inorg. Chem. 223567 (1983)

78. H Ohtaki Pure Appl. Chem. 591143 (1987)

79. J Bjerrum, L H Skibsted Acta Chem. Scand. Ser. A 31673 (1977)

80. S Lechat, M A Khan, G Bouet, F Vierling Inorg. Chim. Acta 21133 (1993)

81. L Chrmurzynski, M Kluczkowski, M Pilarczyk Inorg. Chim. Acta 29373 (1984)

82. M Pilarczyk, W Grzybkowski, L Klinszporn Polyhedron 6 1399 (1987)

83. I M Gusev, Candidate Thesis in Chemical Sciences, St Petersburg State University, St Petersburg, 2011

84. L V Stepakova, Candidate Thesis in Chemical Sciences, St Petersburg State University, St Petersburg, 2007

85. P H Vossos, D R Fitzwater, R E Rundle Acta Crystallogr. 16 1037 (1963)
86. J H Rivers, K J Carroll, R A Jones, E E Carpenter Acta Crystallogr. C 6683 (2010)

87. E P Norkus, A Yu Vashkyalis, I I Reklaitis Zh. Neor. Khim. $312318{(1986)^{\mathrm{e}}}^{\mathrm{C}}$

88. M Klaasen, P Klufers Z. Anorg. Allg. Chem. 619661 (1993)

89. P Klufers, J Schumacher Angew. Chem. 342119 (1995)

90. S V Mikheev, V A Sharnin, V A Shormanov, M A Talanova J. Therm. Anal. 45715 (1995)

91. G Senanayake, D M Muir Electrochim. Acta 33251 (1988)

92. A F Borina Russ. J. Coord. Chem. 33831 (2007) [Koord. Khim. 33845 (2007)]

93. S Minc, W Libus Roczniki Chem. 291073 (1955)

94. W Libus, B Chachulski, L Fraczyk, H Strzelecki Roczniki Chem. 4919 (1975)

95. A O Gorbunov, in VII Vserossiiskaya Konferentsiya Molodykh Uchenykh, Aspirantov i Studentov s Mezhdunarodnym Uchastiem po Khimii i Nanomaterialam. Mendeleev-2013 (The VIIth All-Russian Conference of Young Scientists, Postgraduates and Students with International Participation on Chemistry and Nanomaterials. Mendeleev-2013, St Petersburg, 2013) Vol. 1, p. 101

96. H B Abrahamson, A B Rezvani, J G Brushmiller Inorg. Chim. Acta 226117 (1994)

97. S Maruo, T Saeki Opt. Express 161174 (2008)

98. T A Perera, M Masjedi, P R Sharp Inorg. Chem. 537608 (2014)

99. M J A Rijkenberg, A C Fischer, J J Kroon, L J A Gerringa, K R Timmenmans, H T Wolterbeek, H J N Ole Baar Mar. Chem. 93119 (2005)

100. J Sykora, in Photochemistry and Photophysics of Coordination Compounds (Eds H Yersin, A Vogler) (Berlin, Heidelberg: Springer-Verlag, 1987) p. 193

101. N Armaroli, G Accorsi, F Cardinali, A Listorti, in Photochemistry and Photophysics of Coordination Compounds I (Eds V Balzani, S Campagna) (Berlin, Heidelberg: SpringerVerlag, 2007) p. 69

102. A Ouchi, Z Bastl, J Bohacek, J Subrt, J Pola Surf. Coat. Technol. 2014728 (2007)

103. J Barta, M Pospisil,V Cuba J. Radioanal. Nucl. Chem. 286 $611(2010)$

104. A S Mereshchenko, S K Pal, K E Karabaeva, P Z ElKhoury, A N Tarnovsky J. Phys. Chem. A 1162791 (2012)

105. G Miessler, A D Tarr Inorganic Chemistry (Upper Saddle River, NJ: Prentice Hal, 2004)

106. M A Khan, J Meullemeestre, M J Schwing, F Vierling Inorg. Chem. 283306 (1989)

107. M Khan, G Bouet, F Vierling, J Meullemeestre, M J Schwing Trans. Met. Chem. 21231 (1996)

108. A S Mereshchenko, PhD Thesis, Bowling Green State University, Bowling Green, 2013

109. V F Plyusnin, A V Kolomeets, V P Grivin, S V Larionov, H J Lemmetyinen Phys. Chem. A 1151763 (2011)

110. T Cimei, A R Bizzarri, G Cerullo, S De Silvestri, S Cannistraro Biophys. Chem. 106221 (2003)

111. S Nakashima, Y Nagasawa, K Seike, T Okada, M Sato, T Kohzuma Chem. Phys. Lett. 331396 (2000)

112. D Edington, W M Diffey, W J Doria, R E Riter, W F Beck Chem. Phys. Lett. 275119 (1997)

113. Y Nagasawa, K Fujita, T Katayama, Y Ishibashi, H Miyasaka, T Takabe, S Nagao, S Hirota Phys. Chem. Chem. Phys. 126067 (2010)

114. T Cimei, A R Bizzarri, S Cannistraro, G Cerullo, S De Silvestri Chem. Phys. Lett. 362497 (2002)

115. A R Bizzarri, D Brida, S Santini, G Cerullo, S Cannistraro J. Phys. Chem. B 1164192 (2012)

116. I Delfino, C Manzoni, K Sato, C Dennison, G Cerullo, S Cannistraro J. Phys. Chem. B 11017252 (2006)

117. P G David, P A C da Silva Bull. Chem. Soc. Jpn. 583566 (1985) 
118. E Cervone, F D Camassei, I Giannini, J Sykora J. Photochem. 11321 (1979)

119. E M Glebov, V F Plyusnin, V P Grivin, S A Krupoder, T I Liskovskaya, V S Danilovich J. Photochem. Photobiol. A. 133177 (2000)

120. G Sarova, D Roussanova, B Jeliazkova, N D Yordanov, M A Malik, P O’Brien Spectrochim. Acta, Part A 56351 (2000)

121. B G Jeliazkova, N D Yordanov Inorg. Chim. Acta 203201 (1993)

122. M A Doytcheva, B G Jeliazkova Spectrochim. Acta, Part A 601299 (2004)

123. L Sun, C-H Wu, B C Faust J. Phys. Chem. A 1028664 (1998)

124. C-J Lin, C-S Hsu, P-Y Wang, Y-L Lin, Y-S Lo, C-H Wu Inorg. Chem. 534934 (2014)

125. K Hayaset, R G Zepp Environ. Sci. Technol. 251273 (1991)

126. H Kunkely, A Vogler Inorg. Chim. Acta 357888 (2004)

127. A K Patra, M Nethaji, A R Chakravarty J. Inorg. Biochem. 101233 (2007)

128. E I Isaeva, A A Zheleznyak, V V Gorbunova, V P Pronin Russ. J. Gen. Chem. 831183 (2013) [Zh. Obshch. Khim. 831053 (2013)]

129. S Das, G Ferraudi Inorg. Chem. 251066 (1986)

130. P A C da Silva, P G David Bull. Chem. Soc. Jpn. 552673 (1982)

131. S V Safonov, Candidate Thesis in Chemical Sciences, St Petersburg State University, St Petersburg, 2013

132. R C Sausa, A Gupta, J R White J. Electrochem. Soc. 134 2707 (1987)

a - Quantum Electron. (Engl. Transl.)

b _ Soros Educ. J. (Engl. Transl.)

c _ Glass Phys. Chem. (Engl. Transl.)

d _ J. Exp.Theor. Phys. (Engl. Transl.)

e - Russ. J. Inorg. Chem. (Engl. Transl.) 